\title{
Eficiência terapêutica das formulações lipídicas de anfotericina B
}

\author{
Fabíola Branco Filippin*, Liliete Canes Souza \\ Departamento de Análises Clínicas, Centro de Ciências da Saúde, Universidade Federal de Santa Catarina-UFSC
}

*Correspondência:

F. B. Filippin

Centro de Ciências da Saúde

Campus Universitário $\mathrm{S} / \mathrm{N}$, Trindade

88040-970 - Florianópolis, SC - Brasil

E-mail: ffilippin@bol.com.br
A anfotericina B, fármaco descoberto em 1953, ainda permanece como substância fungicida de escolh a no tratamento da maioria das micoses sistêmicas que acometem pacientes imunocomprometidos. Mesmo com a sua toxicidade e a introdução de antifúngicos azólicos sistêmicos na década de 1980, a potência, o espectro de ação e os quase 50 anos de experiência clínica asseguram sua efetividade tanto para o tratamento das infecções fúngicas quanto para a profilaxia fúngica sistêmica em pacientes neutropênicos. Sua eficácia tem sido julgada a cada medicamento antifúngico novo apresentado aos profissionais de saúde e, por esta razão, numerosas tentativas para reduzir sua nefrotoxicidade especifica surgiram nos últimos anos. Adicionalmente, a necessidade de se instituirem tratamentos agressivos para as micoses sistêmicas invasivas com dosagens necessariamente mais altas motivou o desenvolvimento de diferentes veículos para a administração de anfotericina B. Dentre eles, o encapsulamento de base lipossômica, a formação de complexos lipídicos e dispersões coloidais destacam-se com os melhores resultados na diminuição da toxicidade e aumento da eficácia terapêutica. Serão descritos diversos trabalhos direcionados ao desenvolvimento de preparações lipídicas como veículo para anfotericina $B$, tendo como intuito a utilização dos mecanismos farmacocinéticos dessas formulações a fim de melhorar a distribuição do fármaco nos órgãos-alvo.
Unitermos

- Anfotericina B

- Formulações lipídicas

- Lipossomas

- Emulsões lipídicas

\section{INTRODUÇÃO}

\section{Anfotericina B}

A anfotericina $\mathrm{B}(\mathrm{AB})$, um antibiótico poliênico produzido naturalmente pelo actinomiceto Streptomyces nodosus, foi inicialmente isolada em meados de 1955 (Gold et al., 1956; Vandeputte, Wachtel, Stiller, 1956) e, desde então, apenas alguns agentes com ação antifúngica descoberta tornaram-se viáveis para o tratamento das infecções fúngicas sistêmicas.

No final dos anos 1950, a AB já era utilizada em alguns casos clínicos e em 1965 foi o primeiro agente antifúngico a ser aprovado pela U.S. Food and Drug Administration (FDA) (Wu, 1994; Dismukes, 2000).

Mesmo com a sua elevada toxicidade e a introdução de antifúngicos azólicos sistêmicos na década de 1980 (Dismukes, 2000), a potência, o espectro de ação e os 
quase 50 anos de experiência clínica têm assegurado que a $\mathrm{AB}$ permaneça como fármaco de escolha no tratamento da maioria das micoses sistêmicas que acometem pacientes imunocomprometidos.

A Figura 1 ilustra a estrutura e configuração da $\mathrm{AB}$ tal como relatada por Ganis et al. (1971). O composto contém 37 átomos de carbono formando um anel macrocíclico fechado por lactonização; possui uma cadeia de duplas ligações conjugadas não-substituídas (heptaeno) e, na porção oposta, uma cadeia poli-hidroxilada com sete grupos hidroxila livres, o que lhe confere característica anfipática. Em uma das extremidades da molécula, encontra-se um resíduo micosamina (lactona) com um aminogrupo livre, formando uma cadeia lateral. A molécula tem aproximadamente $24 \AA$ de comprimento, ou seja, o equivalente a meia camada de fosfolipídeo.

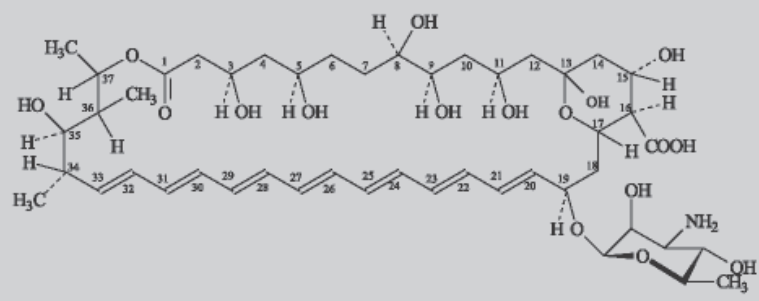

FIGURA 1 - Estrutura química da anfotericina B (Ganis et al., 1971).

\section{Propriedades físico-químicas}

O nome anfotericina deriva da característica anfotérica de sua estrutura molecular, formando tanto sais solúveis em meio ácido como em meio básico (Asher, Schurartzman, 1977).

AAB é pouco solúvel na maioria dos solventes. Com exceção do dimetilsulfóxido (DMSO) e da dimetilformamida, é praticamente insolúvel em soluções aquosas de $\mathrm{pH}$ neutro. A solubilidade de $\mathrm{AB}$ em água pode ser aumentada por adição de lauril sulfato de sódio ou desoxicolato de sódio (DOC). A AB também se dissolve em vesículas de lecitina e colesterol e em esteróides constituintes de membranas naturais (Asher, Schurartzman, 1977).

A formulação convencional comercialmente utilizada, denominada Fungizone ${ }^{\circledR}$ (Bristol-Meyers Squibb), constitui-se de $50 \mathrm{mg}$ de $\mathrm{AB}$, aproximadamente $41 \mathrm{mg}$ de DOC e 20,2 mg de tampão fosfato e será referida no presente trabalho como AB-DOC. O DOC é empregado para solubilização da $\mathrm{AB}$, entretanto o sistema não é homogêneo, podendo apresentar em sua constituição três formas diferentes: monomérica, oligomérica e agregados de AB-
DOC (Legrand et al., 1992) misturados com micelas puras de DOC (Lamy-Freund et al., 1991). Existe equilíbrio, portanto, entre essas formas e suas proporções dependem da diluição empregada (Legrand et al., 1992).

Em estudo com membranas bilamelares comparou-se a capacidade de formação de canais iônicos de $\mathrm{AB}$ frente a membranas contendo ergosterol, colesterol e na ausência destes esteróides. Constatou-se que $\mathrm{AB}$, tanto na forma monomérica quanto agregada, pode formar canais em membranas contendo ergosterol, mas somente a forma agregada formou tais canais em membranas contendo colesterol (Huang et al., 2002). A maior afinidade por ergosterol pode ser demonstrada em estudos nos quais a concentração de $\mathrm{AB}$ necessária para promover permeabilidade foi dez vezes menor para vesículas contendo ergosterol do que para aquelas com colesterol (VertutCroquin et al., 1983; Saint-Pierre-Chazalet et al., 1988).

A interação de $\mathrm{AB}$ com membranas modelo tem sido avaliada por métodos espectroscópicos incluindo fluorescência, dicroismo circular (Bolard et al., 1991; Moribe et al., 1999), absorvância em UV-visível (Huang et al., 2002), ressonância paramagnética eletrônica e ressonância magnética nuclear (Balakrishnan et al., 1993). As técnicas de espectroscopia óptica são sensíveis, pois o comprimento de onda de absorção de $\mathrm{AB}$ é diferente daquele de fosfolipídeos ou de esteróides, além de seu coeficiente de absortividade molar ser muito alto, permitindo detecção de baixas concentrações (Chen, Bittman, 1977).

$\mathrm{O}$ espectro de absorção UV-visível de $\mathrm{AB}$ pode ser observado na Figura 2. Em meio aquoso e em baixas concentrações de $\mathrm{AB}\left(5,0.10^{-7} \mathrm{M}\right)$, o espectro apresenta quatro bandas entre 420 e $320 \mathrm{~nm}$ (pico máximo em $409 \mathrm{~nm}$ ),

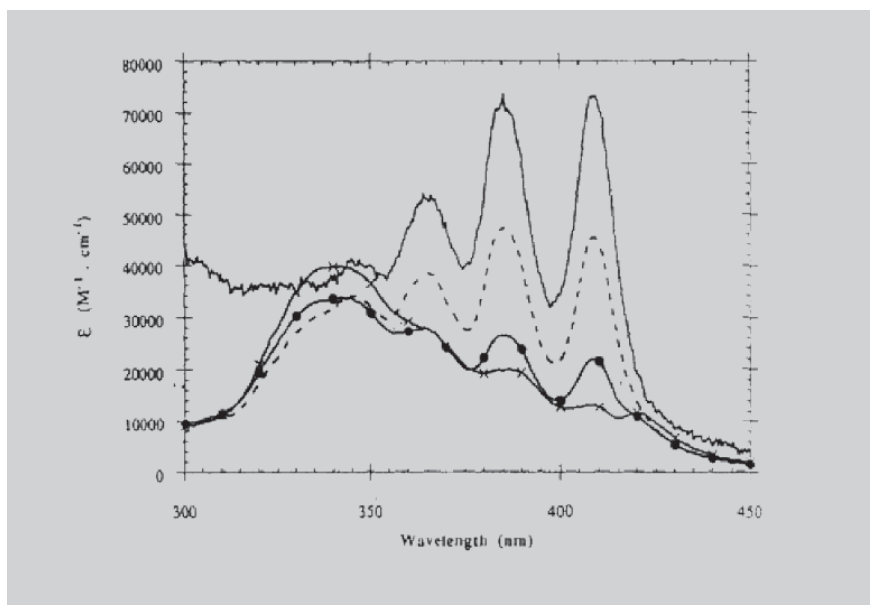

FIGURA 2-Espectro de absorção de anfotericina B dissolvida em DMSO e diluída em tampão fosfato $\mathrm{pH} 7,4$. Concentrações de $5,0 \times 10^{-5} \mathrm{M}(-\times-) ; 5,0 \times 10^{-6} \mathrm{M}(-\bullet-) ; 5,0 \times 10^{-7} \mathrm{M}(---)$; $5,0 \times 10^{-8} \mathrm{M}(-)$ (Tabosa do Egito et al., 1996). 
características de $\mathrm{AB}$ monomérica. Com a elevação da concentração $\left(5,0.10^{-5} \mathrm{M}\right)$, o espectro modifica-se progressivamente até o aparecimento de uma nova banda intensa e achatada próximo de $340 \mathrm{~nm}$, indicando a presença de espécies agregadas (Bolard, Seigneuret, Boudet, 1980; Tabosa do Egito et al., 1996).

$O$ processo de inativação da $\mathrm{AB}$ mostrou-se mediado pela formação de radicais (Schreier et al., 1985) e, possivelmente, o aumento da sua meia-vida in vivo pode ter ocorrido pela diminuição de sua auto-oxidação por ligação à molécula de colesterol (Brajtburg et al., 1985).

\section{Mecanismo de ação}

A AB interage especificamente com o ergosterol, esteróide constituinte exclusivo da parede celular fúngica, levando à formação de poros através de membranas lipídicas (Zygmunt, 1966; Teerlink, De Kruijff, Demel; 1980; Brajtburg et al., 1984; Bolard et al., 1993). A alteração da permeabilidade celular permite, portanto, o escape de pequenos íons e metabólitos, principalmente íons potássio, levando eventualmente à morte celular (Bolard et al., 1993). Estudos realizados por Sokol-Anderson, Brajtburg e Medoff, em 1986, e Beggs, em 1994, demonstraram que a $\mathrm{AB}$ em baixas concentrações (0,16-0,2 $\mathrm{mM})$ produzia perda de $98 \%$ do conteúdo intracelular de íons potássio em cultura de Candida albicans. Outros experimentos indicaram que danos oxidativos produzidos quando da interação de $\mathrm{AB}$ com a membrana celular de eritrócitos (Brajtburg et al., 1985), Candida albicans (SokolAnderson et al., 1988) e em leucócitos polimorfonucleares (PMN) (Marzzullo, Souza, Campa, 1997), apresentaram importante papel no mecanismo de ação lítica do antifúngico.

A afinidade de $\mathrm{AB}$ por colesterol vem sendo há muito estudada, tanto em modelos celulares como em membranas lipossômicas. Assim, embora a AB possua maior afinidade por ergosterol, muitos dos efeitos tóxicos que lhe são atribuídos são resultados da sua capacidade em ligar-se ao colesterol e outros constituintes da membrana celular de mamíferos (White, Peterson, Hartsel, 1989; Bolard et al, 1993; Moribe et al. 1999; Huang et al., 2002).

A ação de $\mathrm{AB}$ sobre as células do sistema imune merece atenção especial, pois este antifúngico é amplamente empregado na terapia de pacientes imunodeprimidos. Algumas ações sobre estas células têm sido relatadas por alguns autores. Os estudos demonstraram que $\mathrm{AB}$ exerce efeitos moduladores interessantes, interferindo em muitas das propriedades de leucócitos, como inibição da quimiotaxia (Bernaudin et al., 1987), na produção de anticorpos (Boggs, Chang, Goundalkar, 1991), nas propriedades funcionais dos leucócitos PMN (Jullien et al., 1991) e diminuição significativa da fagocitose e destruição de Candida albicans (Pallister,
Warnock, 1989). Também foi demonstrada a ocorrência de inibição do "burst" oxidativo de PMN quando incubados com AB-DOC. Além disso, observou-se a redução dessa inibição quando se utilizou $\mathrm{AB}$ associada a emulsão lipídica (AB-emulsão), com composição química similar a quilomícrons naturais da linfa, sugerindo redução na toxicidade frente a leucócitos PMN (Marzzullo, Souza, Campa, 1997).

$\mathrm{O}$ efeito do DOC no metabolismo oxidativo de leucócitos PMN deve ser considerado, pois se relatou a parcial responsabilidade pela inibição da quimiotaxia destas células, quando altas doses de AB-DOC foram utilizadas (Bernaudin et al., 1987).

O aumento do "burst" oxidativo foi mostrado em macrófagos por Wilson, Thorson e Speert (1991), onde sugeriram que $\mathrm{AB}$ ativaria estas células via efeito direto na membrana plasmática, aumentando a capacidade de produção do ânion superóxido. Outros autores, no entanto, propuseram que o acúmulo intracelular do antifúngico, ainda viável, permitiria sua ação direta sobre o fungo fagocitado (Ponce, Pechére, 1990; Martin et al., 1994), fato que auxiliou alguns autores a direcionar o tratamento de infecções fúngicas, cujo agente replicava-se intracelularmente (Graybili, Bocanegra, 1995; Garcia, Adler-Moore, Proffitt, 2000).

Finalmente, um estudo in vivo tendo como modelo experimental o cobaio, demonstrou que uma única dose de $\mathrm{AB}$ não possuiu efeito imunossupressor sobre linfócitos e neutrófilos, mas após 3 doses em dias consecutivos, alterações quimiotáticas e fagocíticas foram observadas; entretanto, os efeitos eram variáveis e não possuíam um padrão de dose-resposta (Drummond et al., 1995).

\section{Toxicidade induzida pela terapia com $A B$}

As reações adversas agudas a $\mathrm{AB}$ tais como febre, calafrios, tremores, náusea, vômitos e dor de cabeça ocorrem freqüentemente e estão principalmente relacionadas à infusão (SchöffskI et al., 1998; Nucci et al., 1999; Walsh et al., 1999; Mora-Duarte et al., 2002). Alterações cardiovasculares como hipotensão, hipertensão e arritmia cardíaca foram observados com menor freqüência (Walsh et al., 1999; Mora-Duarte et al., 2002). Hipocalemia, hipernatremia, diurese aumentada, (Gerbaud et al., 2003), hipomagnesemia, disfunção renal e efeitos tóxicos sobre a medula óssea (anemia, leucopenia e trombocitopenia) estavam associados com administrações repetidas (Schöffski et al., 1998).

$\mathrm{O}$ tratamento com $\mathrm{AB}$ quase sempre resulta em algum grau de disfunção renal, que varia em gravidade de um paciente para outro, sendo claramente uma função da dose total. Em um estudo comparativo entre $\mathrm{AB}$ e Caspofungin (agente com atividade fungicida contra espécies de Candida), 
$24,8 \%$ dos pacientes que foram tratados com $\mathrm{AB}(0,6$ $1,0 \mathrm{mg} / \mathrm{kg} / \mathrm{dia}$ ) apresentaram nefrotoxicidade comprovada através de achados laboratoriais (Mora-Duarte et al., 2002).

Um estudo em células renais de ratos conduzido por Varlam et al. (2001) sugeriu que a AB induzia apoptose em células tubulares renais e em células intersticiais em taxa diretamente proporcional à concentração. Observou-se $90 \%$ de apoptose e necrose com a concentração máxima utilizada $(5,0 \mathrm{mg} / \mathrm{mL})$, sendo que em doses menores, mínima apoptose foi relatada. Observou-se, em estudos anteriores, que o efeito tóxico foi máximo nos túbulos (hipocalemia, hipostenúria, diminuição da capacidade de excretar ácidos), mas também envolveu os glomérulos (diminuição da depuração de creatinina, com ou sem azotemia) (Burgess, Birchall, 1972; Bhathena et al., 1978; Gerkens, Branch, 1980; Heidemann et al., 1983; Sabra et al., 1990).

Durante o curso do tratamento com AB, a nefrotoxicidade foi constatada através de concentrações séricas elevadas de creatinina (Schöffski et al., 1998; Walsh et al., 1999; Mora-Duarte et al., 2002), muitas vezes até três vezes o limite superior da normalidade (Walsh et al., 1999).

Os efeitos neurotóxicos em pacientes tratados com injeção endovenosa de AB são raros. Observam-se hipertermia, confusão mental, depressão, delírio, comportamento psicótico, convulsão, tremores, perda de audição, opacidade da visão, dentre outras alterações acompanhadas por degeneração da bainha de mielina (Racis et al., 1990).

A cardiotoxicidade foi descrita especialmente pela indução de arritmia ventricular, secundária a hipocalemia em pacientes com função renal diminuída, que são suscetíveis a essa alteração eletrolítica (Craven, Gremillion, 1985; Schöffski et al., 1998). Sua ocorrência é rara se o balanço eletrolítico for mantido, mas para a maioria dos pacientes, a manutenção requer suplemento de potássio e magnésio (Barton et al., 1984), apesar de alguns autores terem observado a persistência de arritmia após suplementação (Schöffski et al., 1998).

A toxicidade de $\mathrm{AB}$ também foi avaliada por Wilson e Feldman (1979), em 20 crianças com câncer, apresentando infecção fúngica sistêmica, sendo observado que o segundo efeito adverso mais significativo, logo após azotemia, foi a anemia normocítica normocrômica acompanhada de trombocitopenia.

\section{Espectro de ação}

A atividade da $\mathrm{AB}$ é máxima na faixa de $\mathrm{pH} 6,0 \mathrm{a}$ 7,5 e a ação pode ser fungistática ou fungicida, dependendo da concentração sérica e tecidual do antifúngico e da suscetibilidade do patógeno (Vartivarian, Anaissie, Bodey, 1993).
A AB possui atividade contra a maioria das espécies de Candida spp., como foi verificado por alguns autores (Davey et al., 1998; Clancy, Nguyen, 1999; Burgess et al, 2000; Pfaller et al., 2002). Em um estudo utilizando-se cepas isoladas de pacientes hospitalizados em todo o continente americano, a Candida albicans foi a espécie mais suscetível, verificado pela concentração mínima de $90 \%$ de inibição $\left(\mathrm{MIC}_{90}\right)$ de $1,0 \mathrm{mg} / \mathrm{mL}$, seguida de cepas resistentes de Candida glabrata $\left(\mathrm{MIC}_{90} 4,0 \mathrm{mg} / \mathrm{mL}\right)$, Candida parapsilosis ( $\mathrm{MIC}_{90} 4,0 \mathrm{mg} / \mathrm{mL}$ ) e Candida krusei ( $\mathrm{MIC}_{90}$ $8,0 \mathrm{mg} / \mathrm{mL}$ ) (Pfaller et al., 2002).

AAB também apresentou atividade contra algumas cepas de Candida lusitaniae (Davey et al., 1998), apesar de um estudo realizado por Clancy e Nguyen (1999) ter demonstrado haver resistência de $\mathrm{AB}$ frente a determinadas cepas isoladas de pacientes com candidemia, sendo que a concentração mínima inibitória (MIC) foi de $1,5 \mu \mathrm{g} / \mathrm{mL}$. Em outro estudo realizado recentemente por Pfaller et al. (2004), cepas raras da espécie Candida demonstraram ser sensíveis a $\mathrm{AB}$ obtendo-se MIC de $0,5 \mu \mathrm{g} / \mathrm{mL}$ para $C$. lusitaniae através do método de microdiluição.

Em relação aos fungos filamentosos, a $\mathrm{AB}$ possui amplo espectro de ação, incluindo Aspergillus fumigatus (MIC 1,0-2,0 mg/mL), Aspergillus flavus (MIC 1,0 mg/mL) (Espinel-Ingroff et al., 1997; Arikan et al., 1999), Fusarium oxysporum (MIC $2,0 \mathrm{mg} / \mathrm{mL}$ ), Fusarium solani (MIC 1,0-2,0 mg/mL), Rhizopus arrhizuz (MIC 0,2-0,5 mg/mL) (Espinel-Ingroff et al., 1997) e Paracoccidioides brasiliensis (1,0-0,25 mg/mL) (Hahn, Hamdan, 2000).

O estudo realizado por Serrano et al. (2003), comparou a atividade in vitro de vários antifúngicos, incluindo $\mathrm{AB}$. Os autores avaliaram o MIC para cepas de Aspergillus fumigatus e cepas isoladas não-fumigatus e obtiveram variação de $0,25-2,0 \mathrm{mg} / \mathrm{mL}$ e $0,12-1,0 \mathrm{mg} / \mathrm{mL}$ para $A$. fumigatus e espécies não-fumigatus, respectivamente, demonstrando que as cepas de Aspergillus spp. são mais suscetíveis a $\mathrm{AB}$ se comparadas com $A$. fumigatus.

A AB também possui atividade contra Histoplasma capsulatum (Gonzales et al., 2000; Li et al., 2000), Cryptococcus neoformans (Davey et al., 1998), Coccidioides immitis e Blastomyces dermatitidis (Li et al., 2000). Sua atividade foi considerada limitada contra algumas cepas de Fusarium spp., apesar de um estudo recente ter demonstrado que a resistência in vitro nesta espécie não foi freqüente $\left(\mathrm{MIC}_{90} 1,0-4,0 \mathrm{mg} / \mathrm{mL}\right.$ ) (EspinelIngroff et al., 1997).

Cepas de Leishmania (Viannia) braziliensis também foram suscetíveis a ação de $\mathrm{AB}$, sendo também empregada na terapia de leishmaniose visceral (Davidson et al., 1991; Durand et al., 1998) e mucocutânea (Amato et al., 2000). 


\section{Mecanismos de resistência a $A B$}

Do ponto de vista bioquímico, a resistência aos antibióticos poliênicos poderia estar associada ao aumento ou diminuição dos esteróides da membrana, especialmente ergosterol e seus precursores. Em um estudo recente, Young et al. (2003) conduziram um experimento baseado no fato de que a ação lítica de $\mathrm{AB}$ somente ocorreria se houvesse interação do fármaco com ergosterol da membrana fúngica. Os autores, portanto, desenvolveram uma cepa mutante de Candida lusitaniae com defeito na biossíntese de ergosterol (C. lusitaniae ERG6"), na qual foi observada resistência in vitro à $\mathrm{AB}$. A ausência de ergosterol foi também apontada como responsável pela resistência de microorganismos frente à $\mathrm{AB}$ em um estudo anterior. A incubação prévia de promastigotas da Leishmania mexicana com cetoconazol (antifúngico que atua na inibição da biossíntese de ergosterol) reduziu a ligação da $\mathrm{AB}$ a essas células e a conseqüente formação de poros, efeitos que somente ocorreram em função da concentração do imidazólico, que resultou no acúmulo progressivo de lanosterol com redução drástica de ergosterol (Ramos et al., 1994). Apesar de estudos in vitro terem demonstrado interação entre $\mathrm{AB}$ e antifúngicos azólicos, Barchiesi et al. (2000) não relataram efeito antagônico in vitro frente $C$. neoformans e in vivo na terapia contra criptococose em camundongos.

Uma segunda possibilidade seria a ocorrência de outras modificações fenotípicas com alterações na síntese de proteínas e enzimas, como por exemplo, a produção de uma enzima capaz de degradar o antifúngico. Assim, cepas de Cryptococcus neoformans que foram expostas a baixas concentrações de $\mathrm{AB}$ por 48 horas apresentaram modificações no metabolismo lipídico sendo de substancial importância a diminuição no conteúdo de ergosterol (Pianscatelli, Hamdan, 1994). Outro estudo utilizando promastigotas de Leishmania donavani revelou a mudança no metabolismo lipídio na membrana do parasita como mecanismo de resistência ao fármaco, aumentando sua fluidez e diminuindo a interação com AB (Mbongo et al., 1998). Ambos os estudos demonstraram redução efetiva na atividade lítica do antifúngico, evidenciando que a presença de ergosterol era essencial na sua atuação.

\section{FORMULAÇÕES LIPÍDICAS DE AB}

O uso de doses elevadas de AB-DOC, mais efetivas do que as convencionais (acima de $1,0 \mathrm{mg} / \mathrm{kg} / \mathrm{dia}$ ), tornase limitado pelos efeitos tóxicos, bem como em seu uso profilático. Para circundar estes problemas, desenvolveram-se formulações menos tóxicas e novos métodos para veiculação de $A B$.
Muitos trabalhos foram direcionados ao desenvolvimento de preparações lipídicas como veículo para fármacos, como lipossomas (Lopez-Berestein et al., 1983; Hospenthal, Rogers, Mills, 1988; Hospenthal, Gretzinger, Rogers, 1989; Chopra et al., 1991), complexos lipídicos (Janoff et al., 1988; Balakrishnan, Easwaran, 1993) e emulsões (Kirsh et al., 1988; Illum et al., 1989; Miyazaki et al., 1990; Chavanet et al., 1992a; Chavanet et al., 1992b; Souza et al., 1993). Os lipossomas foram inicialmente utilizados para estudar o fluxo de íons através das membranas celulares (Borisova, Erminshkin, Silberstein, 1979; Kasumov et al., 1979; VertutCroquin et al., 1983; Cybulska et al., 1985), mas as principais razões dos estudos posteriores foram a necessidade de reduzir a toxicidade e a possibilidade de utilização dos mecanismos farmacocinéticos dessas formulações, a fim de melhorar a distribuição de fármacos nos órgãos-alvo (Kan et al., 1991; Walsh et al., 1998; Adedoyin et al., 2000; Bekersky et al., 2002). Muitos fármacos têm sido incorporados a lipossomas e alguns destes estudos demonstraram que AB-lipossômico ou $\mathrm{AB}$-emulsão eram tão eficazes quanto $\mathrm{AB}-\mathrm{DOC}$ no tratamento de infecções fúngicas em animais, sendo ainda menos tóxicas (Graybili, Bocanegra, 1995; Souza et al., 1999; Shadkchan, Segal, 2001).

As formulações lipídicas são de difícil preparação e o desenvolvimento industrial torna-se importante. Desta forma, três formulações foram desenvolvidas pela indústria farmacêutica:

- AmBisome, uma preparação lipossômica de vesículas unilamelares pequenas, constituídas de fosfatidilcolina hidrogenada de soja, colesterol, diesteroilfosfatidilglicerol (DMPG) e AB em razão molar de 2:1:0,8:0,4 (AmBisome ${ }^{\circledR}$, Fujisawa Healthcare Inc., Deerfiled, IL), aprovada pelo FDA em 1997;

- $\mathrm{ABCD}$, uma dispersão coloidal de $\mathrm{AB}$ em sulfato de colesterila sódica em razão molar de 1:1, formulada em partículas discóides (Amphocil ${ }^{\circledR}$, Sequuspharmaceuticals Inc., Menlo Park, CA, EUA), aprovada pelo FDA em 1996.

- ABLC, um complexo lipídico com AB de estrutura multilamelar "ribbon-like" constituído de diesteroilfosfatidilcolina (DMPC) e diesteroilfosfatidilglicerol (DMPG) em razão molar de 7:3 com $36 \mathrm{~mol} \%$ de $\mathrm{AB}$ (Abelcet $^{\mathbb{B}}$, The Liposome Company Inc., Princeton, NJ) licenciada no Reino Unido e aprovada pelo FDA em 1995.

Estas formulações diferem na estrutura, forma, tamanho, composição lipídica e conteúdo de $\mathrm{AB}$ (Dismukes, 2000).

A possibilidade do uso de concentrações mais elevadas de $\mathrm{AB}$ veiculada em formulações lipídicas ainda menos tóxicas que AB-DOC, tem relevada importância. Entretan- 
to, efeitos indesejáveis como febre, calafrio, rigidez, sonolência, discreta elevação dos testes de função hepática, disfunção renal e toxicidade cardiopulmonar foram documentadas em pacientes que receberam AmBisome (Walsh et al., 1998). Desta forma, considerando a possível ocorrência destes efeitos, uma avaliação clínica rotineira deve ser realizada assim que a terapia seja instituída.

\section{Eficiência e toxicidade das formulações lipídicas}

Embora tanto AB-DOC quanto AB lipossômico sejam captados pelos órgãos do sistema reticuloendotelial (SRE), foi observado um acúmulo preferencial da formulação lipossômica no fígado e nos pulmões, em estudo realizado em um paciente com aspergilose invasiva (Heinemann et al., 1997). A captação preferencial dos lipossomas pelo SRE, principalmente fígado, medula óssea (Groll et al., 2000) e baço (Garcia, et al., 2000) pode, em parte, explicar a incidência de hepatotoxicidade observada após administração de várias doses de AmBisome (Proffit et al., 1991; Lee et al., 1994; Heinemann et al., 1997), acompanhada de diminuição da toxicidade renal e cardíaca (Lee, et al., 1994). A administração de ABCD também reduziu a disponibilidade de $\mathrm{AB}$ nos rins, diminuindo a nefrotoxicidade, mas aumentou sua concentração nos órgãos do SRE (Fielding et al., 1992; Groll et al., 2000).

Com o aumento da captação de $\mathrm{AB}$ pelos órgãos do SRE, a eficiência terapêutica poderia estar reduzida em outros órgãos, especialmente no tecido renal, muito suscetível a candidíase. Entretanto, isso aparentemente não ocorreu quando foram utilizados lipossomas multilamelares grandes constituídos de fosfolipídeos utilizados como veículo para $\mathrm{AB}$, que, mesmo sendo rapidamente removida pelo SRE, permaneceu efetiva no tratamento de candidíase disseminada com grande envolvimento renal (Lopez-Berestein et al., 1983).

Os lipossomas são amplamente captados pelos macrófagos (Van Etten et al., 1998a). Como essas células são infectadas na leishmaniose visceral, Davidson et al. (1991) utilizaram AmBisome (50 mg/dia) em um caso de resistência aos demais agentes terapêuticos convencionalmente empregados. Além do paciente não ter sofrido os efeitos tóxicos de $\mathrm{AB}$, a terapia resultou em resposta clínica favorável e negativação parasitológica (21 dias), fato incomum para um caso refratário à medicação, especialmente quando comparado com outro paciente que recebeu AB-DOC, tendo este respondido mais lentamente à terapia (5 meses para cura). Croft, Davidson e Thornton (1991) relataram um estudo com o mesmo perfil e obtiveram resultados similares.
A erradicação de lesões orofaríngeas resultantes de co-infecção por Leishmania (Viannia) braziliensis em paciente com o vírus da imunodeficiência humana (HIV) foi observada após tratamento com AmBisome, demonstrando superioridade clínica, quando comparada com medicação convencional (Amato et al., 2000). Dietze et al. (1993) utilizaram $\mathrm{ABCD}(2,0 \mathrm{mg} / \mathrm{kg} / \mathrm{dia})$ no tratamento desta doença, sendo que todos os pacientes curados tratavam-se por 7 a 10 dias. O tempo necessário de internação e terapia foi reduzido de 4 (tratamento convencional com agentes antimoniais) para 1 semana, diminuindo, assim, os custos hospitalares. Estes trabalhos demonstraram que as formulações lipídicas de $\mathrm{AB}$, com sua reduzida toxicidade, também podem tornar-se úteis no tratamento de uma doença cujo agente etiológico é um protozoário.

\section{Estudos que avaliaram AmBisome}

\section{Estudos em animais}

Um estudo em camundongos demonstrou que para a erradicação de um modelo de infecção pulmonar por Blastomyces dermatitidis foram necessárias doses superiores a 7,5 mg/kg de AmBisome (Clemons, Stevens, 1993). Observou-se que, em coelhos, a eficiência de AmBisome era parcialmente dose-dependente, já que concentrações entre 7,5 e $15 \mathrm{mg} / \mathrm{kg} / \mathrm{dia}$ aumentavam a eficiência, mas doses acima desta faixa não resultavam em maior controle da infecção (Clemons et al., 2002).

Alguns investigadores relataram eficiência terapêutica equivalente entre AmBisome e AB-DOC (Hopfer, Mehta, Lopez-Berestein, 1987), enquanto outros encontraram significativa redução na atividade antifúngica para a formulação lipídica (Hopfer et al., 1984; Ralph et al., 1991). Pahls e Schaffner (1994) também compararam AmBisome com AB-DOC quanto à atividade antifúngica in vitro e em modelos de candidíase sistêmica e localizada em camundongos imunocomprometidos. Demonstrouse que a formulação lipídica apresentava atividade antifúngica 4 a 8 vezes menor em todos os experimentos testados. Em outro estudo com exposição de Candida albicans ao antifúngico por tempo curto, a atividade de AmBisome foi significativamente menor que a de ABDOC (Van Etten, Groot, Bakker-Woudenberg, 1993). Dois anos mais tarde, ainda em relação a AmBisome, os autores relataram experimentos que comprovavam uma diminuição nos efeitos deletérios das células fagocíticas sobre $C$. albicans, sendo necessárias concentrações 32 vezes maiores de $A B$ para obtenção da atividade antifúngica, se comparadas com AB-DOC (Van Etten, Snijders, Bakker-Woudenberg, 1995). 
Os experimentos in vivo com AmBisome mostraram ser esta formulação menos tóxica, mas também menos ativa nas mesmas concentrações que AB-DOC. Clemons e Stevens (1993) avaliaram a eficiência de AmBisome num modelo experimental de blastomicose pulmonar em camundongos e relataram que em doses equivalentes, AB-DOC foi superior a AmBisome, em relação ao prolongamento da sobrevivência e à redução das leveduras viáveis nos órgãos e que $3,0 \mathrm{mg} / \mathrm{kg}$ da formulação lipossômica foram equivalentes a $1,0 \mathrm{mg} / \mathrm{kg}$ de AB-DOC. Concentrações elevadas e ao mesmo tempo eficientes puderam ser administradas sem toxicidade, sendo estimado que AmBisome foi, no mínimo, 20 vezes menos tóxico que AB-DOC em animais infectados. Resultados contraditórios foram relatados em estudo conduzido por Alder-Moore et al. (1991). Utilizando modelo de candidíase e criptococose em camundongos, demonstraram que AmBisome foi equivalente a AB-DOC .

Estudo mais recente conduzido por Leenders et al. (1997), comparando a eficiência terapêutica de AmBisome e AB-DOC em um modelo de aspergilose disseminada em ratos, demonstrou que a formulação lipossômica foi superior na redução da disseminação pulmonar e hepatoesplênica de A. fumigatus. Os autores justificaram a eficiência superior, pela acumulação de AmBisome nestes órgãos, fato constatado um ano antes por Van Etten et al. (1995). Em um modelo experimental de meningite por Cryptococcus neoformans e Candida albicans em coelhos, a terapia com AmBisome $(7,5,15$ e $22,5 \mathrm{mg} / \mathrm{kg})$ foi comparada a AB-DOC $(1 \mathrm{mg} / \mathrm{kg})$ e ao fluconazol $(80 \mathrm{mg} / \mathrm{kg})$. Observou-se que os animais tratados com AmBisome mostraram melhora clínica aparente, mínimas manifestações neurológicas, reduzido comprometimento histopatológico e maior tempo de sobrevivência. A terapia com fluconazol e ABDOC também foi eficiente, mas inferior a AmBisome (Clemons et al., 2002).

\section{Estudos em humanos}

A formulação AmBisome foi bem tolerada em pacientes neutropênicos febris na forma de tratamento empírico, como relatado por Walsh et al. (1998). Os autores observaram efeitos indesejáveis mínimos relacionados à infusão e somente $5 \%$ dos pacientes fizeram uso de pré-medicação, sendo o estudo conduzido em 36 pacientes recebendo concomitantemente tratamento quimioterápico. Devido à falta de sensibilidade dos métodos de diagnóstico que estabelecem infecções fúngicas, a terapia empírica tem sido proposta para pacientes com neutropenia febril persistente que não respondem ao tratamento com antibióticos. Neste tipo de tratamento, o fármaco é administrado em caso de suspeita de infecção fúngica (Walsh et al., 1999).

Em indivíduos jovens, a terapia com AmBisome também resultou em baixa incidência de reações adversas, bem como de anormalidades das funções orgânicas. Como observado por Tollemar, Duraj e Ericzon (1990), após transplante de fígado, um paciente de 9 meses com candidemia foi submetido à terapia com AmBisome $(1,0 \mathrm{mg} / \mathrm{kg} / \mathrm{dia}$, durante $15 \mathrm{dias})$, demonstrando boa tolerância ao tratamento e raros efeitos adversos.

AmBisome foi administrado como terapia empírica em 16 crianças com câncer e profundamente granulocitopênicas. Apesar da capacidade de cura não ter sido avaliada devido à comprovação de infecção por Candida spp. em apenas 4 crianças, Emminger et al. (1994) não observaram reações agudas relacionadas à infusão.

Em alguns estudos, AmBisome foi administrado em indivíduos que não toleraram ou não responderam às doses terapêuticas de AB-DOC (Coker et al., 1991; Hudson, Scott, Warnock,1991; Ringdén et al., 1991; Mills et al., 1994).

Neste sentido, a administração de AmBisome resultou em sucesso no tratamento de candidíase hepática num paciente leucêmico (Hudson, Scott, Warnock,1991), de criptococose disseminada em 3 pacientes HIV-positivo (Schürmann et al., 1991), de aspergilose pulmonar em 13 pacientes neutropênicos (Mills et al., 1994), de infecções fúngicas invasivas causadas por Candida spp. e Aspergillus spp. em 37 pacientes imunocomprometidos (Ringdén et al., 1991).

Apesar dos diversos casos bem-sucedidos relatados acima, quando a infecção fúngica se apresentava avançada não se obteve resposta clínica favorável com a utilização de AmBisome. No tratamento de 3 indivíduos HIV-positivo com meningite criptocócica, apenas um sobreviveu (Coker et al., 1991). A ineficiência desta terapia também foi observada por Ringdén et al. (1991) em $27 \%$ dos casos de aspergilose ou candidíase invasivas avaliados, sendo que $53 \%$ destes morreram por infecção fúngica. $\mathrm{Na}$ aspergilose pulmonar, foi necessário o uso de doses 4 vezes maiores de AmBisome para que fossem atingidas concentrações pulmonares terapêuticas de AB (Ringdén et al., 1991).

A associação de terapia imunossupressiva e AmBisome em concentração de $3 \mathrm{mg} / \mathrm{kg} / \mathrm{dia}$ em pacientes que sofreram transplante de fígado foi a causa do insucesso na cura de aspergilose invasiva. Segundo Fisher et al. (1999), seis destes pacientes com insuficiência renal e respiratória morreram e a análise tecidual post-mortem revelou Aspergillus spp. em 3 dos casos. Assim, embora a dose recomendada de AmBisome seja 
$3 \mathrm{mg} / \mathrm{kg} /$ dia, no referido artigo esta concentração foi discutida pelos autores e considerada como abaixo da concentração terapêutica tendo em vista que os pacientes mortos apresentavam infecção ativa.

A necessidade de doses maiores de AmBisome em certos tratamentos foi questionada por Lequaglie (2002) em que, com concentrações relativamente baixas $(1,0-2,2 \mathrm{mg} / \mathrm{kg} / \mathrm{dia})$, AmBisome foi administrado desde o início do tratamento em um grupo de pacientes com infecção pulmonar fúngica (Aspergillus fumigatus e Candida tropicalis foram isolados de lavado broncoalveolar) e sua segurança e efetividade pôde ser comprovada pela erradicação dos agentes infecciosos.

Os estudos citados a seguir perfazem uma amostragem das reações adversas relatadas na literatura de AmBisome. Em termos gerais a formulação foi bem tolerada e a indução de toxicidade ocorreu em poucos dos pacientes observados, sendo que em alguns casos não ficou estabelecido se as alterações foram devidas ao tratamento ou à vigência de outras doenças graves. Os efeitos colaterais mencionados foram aumento de creatinina sérica (Schürmann et al., 1991; Tollemar et al., 1993); náusea persistente, febre, calafrios e tremores (Mills et al., 1994; Chopra et al., 1991) ocorreram em pouquíssimas ocasiões. Estudos mais recentes também relataram diminuição de efeitos colaterais, tais como: dispnéia, hipotensão e taquicardia, bem como baixa ocorrência de hipocalemia e de aumento da creatinina sérica (Prentice, Hann, Herbrecht, 1997; Klastersky, 2004).

Apesar de todas as vantagens ligadas à administração de AmBisome, também foram relatados casos de reações anafiláticas. O primeiro relato foi de dois casos em pacientes com candidíase sistêmica e a reação foi relacionada aos componentes lipossômicos, pois após reverter o quadro de anafilaxia, o tratamento antifúngico com ABDOC foi retomado e não houve mais desenvolvimento de reações anafiláticas (Laing et al., 1994). Também foram relatados casos de uma criança de dois anos (Vaidya et al., 2002) e de um paciente com aspergilose semi-invasiva (Lampo et al., 2003), que estavam sendo tratados com AmBisome e não eram alérgicos à anfotericina $\mathrm{B}$, confirmando a hipótese de a reação ter ocorrido em função dos componentes lipídicos da formulação.

\section{Estudos que avaliaram Anfotericina em dispersão coloidal (ABCD)}

Um dos primeiros estudos in vitro avaliando a toxicidade de ABCD foi desenvolvido por Forster, Washington e Davis (1988), demonstrando que eritrócitos sofriam lise em maior tempo e em menor taxa quando in- cubados com ABCD, se comparado com AB-DOC. Com a comprovação de menor índice de toxicidade celular, avaliou-se, embora anos mais tarde, a eficácia antifúngica in vitro contra 15 espécies patogênicas de fungos demonstrando o decréscimo na atividade de $\mathrm{ABCD}$ (4 vezes) em relação à $\mathrm{AB}-\mathrm{DOC}$ (Hanson, Stevens, 1992).

\section{Estudos em animais}

Quanto à eficiência terapêutica da formulação $\mathrm{ABCD}$, observou-se um bom índice curativo em comparação com outras formulações lipídicas. $\mathrm{ABCD}$ manteve sua ação antifúngica no tratamento de aspergilose em coelhos (Patterson et al., 1989) e sua administração em camundongos com candidíase levou à redução do número de unidades formadoras de colônia (UFC) nos rins, sugerindo ação do antifúngico mesmo com as baixas concentrações atingidas nesse órgão (Fielding et al., 1991).

Em relação a efeitos adversos, Fielding et al. (1992), utilizando cães, relataram que $\mathrm{ABCD}$ produziu efeitos tóxicos similares ao induzidos por AB-DOC, mas em menor intensidade. Durante 14 dias doses diárias de $5,0 \mathrm{mg} / \mathrm{kg}$ de $\mathrm{ABCD}$ produziram efeitos similares a $0,6 \mathrm{mg} / \mathrm{kg}$ de AB-DOC. Para doses superiores a 0,6 e $1,2 \mathrm{mg} / \mathrm{kg}$ de $\mathrm{ABCD}$, os valores séricos de creatinina e uréia foram bastante elevados e a osmolaridade da urina diminuiu. Elevação significativa das enzimas hepáticas (transaminases e fosfatase alcalina) foi observada nos animais que receberam doses superiores a $2,5 \mathrm{mg} / \mathrm{kg}$ de ABCD. Hiperfosfatemia e valores elevados de creatina fosfoquinase e $\gamma$-glutamil transpeptidase ocorreram após $5,0 \mathrm{mg} / \mathrm{kg}$ de $\mathrm{ABCD}$. Todos os parâmetros bioquímicos estavam elevados após doses de 10,0 mg/ $\mathrm{kg}$.

\section{Estudos em humanos}

A anfotericina $\mathrm{B}$ em dispersão coloidal ( $\mathrm{ABCD}$ ) foi bem tolerada em administração de dose única em voluntários saudáveis. Entretanto, o aumento progressivo da concentração levou ao aumento da incidência de efeitos colaterais, tais como vômitos, náusea e calafrio. Após administração de $1,5 \mathrm{mg} / \mathrm{kg} /$ dia de $\mathrm{ABCD}, 50 \%$ dos indivíduos apresentaram tais efeitos e em 2 pacientes foram observadas febre e taquicardia (Sanders et al., 1991). Em outro estudo, agora no tratamento de leishmaniose $(2,0$ $\mathrm{mg} / \mathrm{kg} / \mathrm{dia}$ ), febre e calafrios foram os efeitos colaterais mais comuns (Dietze et al., 1993). Foram verificados alguns casos de flebite e os testes para avaliação da função renal e hepática não sofreram alteração (Dietze et al., 1993; Sanders et al., 1991).

O tratamento de infecção fúngica invasiva com $\operatorname{ABCD}(4 \mathrm{mg} / \mathrm{kg} / \mathrm{dia})$ em taxa de $1 \mathrm{mg} / \mathrm{kg} / \mathrm{h}$ em $133 \mathrm{pa}-$ cientes com insuficiência renal, mostrou a ocorrência 
de alguns efeitos colaterais, sendo os mais comuns febre $(18 \%)$ e tremores $(41 \%)$. Efeitos relacionados à infusão também foram observados em $56 \%$ dos casos, sendo que 6 destes pacientes tiveram que suspender a terapia com ABCD. Apesar disto, foi observado pequeno decréscimo na concentração sérica de creatinina durante o tratamento, o que permitiu aos autores inferirem sobre a efetividade e alta tolerância de ABCD (Anaissie et al., 1998).

Bowden et al. (1996), através da observação de tremores, calafrio e hipotensão em pacientes que receberam até $8,0 \mathrm{mg} / \mathrm{kg}$ de $\mathrm{ABCD}$, verificaram que a dose máxima tolerada era de $7,5 \mathrm{mg} / \mathrm{kg}$, uma vez que os efeitos tóxicos relacionados à infusão foram toleráveis e a toxicidade renal observada foi mínima. Neste estudo de fase I, foram tratados 75 pacientes submetidos a transplante de medula com infecção fúngica invasiva (Candida spp. ou Aspergillus spp.). Dos pacientes com fungemia, 53\% foram responsivos ao tratamento, $52 \%$ com pneumonia tiveram resposta completa ou parcial, sendo que a taxa de sobrevivência desse estudo foi de $31 \%, 63 \%$ dos quais com candidíase hepatoesplênica.

A erradicação de Cryptococcus neoformans no líquido cerebroespinhal foi relatada no tratamento de 4 pacientes imunocomprometidos apresentando meningite. Os casos foram relatados por Valero e Graybill (1995), em que todos os pacientes foram inicialmente tratados com $A B-D O C$, que foi subseqüentemente substituída por $\mathrm{ABCD}(4 \mathrm{mg} / \mathrm{kg} / \mathrm{dia})$.

White et al. (1997) compararam a terapia de ABCD e AB-DOC em 572 pacientes, nos quais 161 estavam com infecção fúngica por Aspergillus spp. Foram observados melhor resposta terapêutica, menor índice de mortalidade e redução da toxicidade renal nos pacientes que receberam $\mathrm{ABCD}$, sugerindo que a formulação lipídica era superior à terapia convencional.

\section{Estudos que avaliaram ABLC}

\section{Estudos em animais}

Os primeiros estudos in vivo avaliando $\mathrm{AB}$ em complexo lipídico (ABLC) foram relatados por Clark et al. (1991), em estudo com camundongos. Os valores plasmáticos de $\mathrm{ABLC}$ encontrados foram bem menores quando comparados com AB-DOC. As toxicidades reduzidas $\left(\mathrm{LD}_{50}>40 \mathrm{mg} / \mathrm{kg}\right.$ ) permitiram o uso de concentrações de $\mathrm{AB}$ consideradas tóxicas para $\mathrm{AB}-\mathrm{DOC}\left(\mathrm{LD}_{50}\right.$ $3,0 \mathrm{mg} / \mathrm{kg}$ ), permitindo melhor resposta terapêutica. A ABLC foi efetiva contra infecção sistêmica em camundongos causada por Candida spp. C. neoformans e $H$. capsulatum e em animais imunodeprimidos infectados com Candida spp., A. fumigatus e H. capsulatum.
Perfect e Wright (1994) avaliaram a eficiência de ABLC em meningite criptocócica e candidíase disseminada experimental. Não houve toxicidade aparente de ABLC $(10 \mathrm{mg} / \mathrm{kg} / \mathrm{dia})$, quando administrada por injeção endovenosa durante 10 dias em coelhos. No tratamento da meningite, foram eficazes $1 \mathrm{mg} / \mathrm{kg}$ de AB-DOC ou $10 \mathrm{mg} / \mathrm{kg}$ de ABLC, mas a esterilização do líquor foi mais rápida com a formulação lipídica. Na candidíase renal, a diminuição de potência com ABLC ficou aparente, pois foram necessárias doses mais elevadas dessa formulação para a obtenção de efeito terapêutico similar ao de $\mathrm{AB}-\mathrm{DOC}$, possivelmente devido à menor captação de ABLC pelo tecido renal.

A atividade antifúngica de ABLC também foi avaliada por Swenson et al. (1998), em que testes in vitro foram realizados a fim de avaliar a eficiência terapêutica através do papel das fosfolipases fúngicas extracelulares. Verificou-se que cepas de $C$. albicans com deficiência na produção de fosfolipases apresentaram resistência à ABLC, mas foram sensíveis à AB-DOC. Entretanto, in vivo, foi observado que todas as cepas de $C$. albicans e $A$. fumigatus eram suscetíveis a ABLC e AB-DOC. Os autores sugeriram, a partir deste fato, que a atividade antifúngica de $\mathrm{ABLC}$ foi devida à liberação seletiva de $\mathrm{AB}$ ativa através da ação das lipases fúngicas ou de outras células do hospedeiro (outras fontes de fosfolipases, como células fagocíticas e endoteliais) e que os testes in vitro não demonstraram a real efetividade de ABLC.

\section{Estudos em humanos}

Kan et al. (1991) administraram ABLC $(0,1 ; 0,25 \mathrm{e}$ $0,5 \mathrm{mg} / \mathrm{kg}$ em três dias alternados) em voluntários saudáveis. $\mathrm{O}$ antifúngico causou sonolência em $75 \%$ dos indivíduos e em cerca de $37 \%$ provocou elevação transitória das transaminases, aparentemente assintomática, cujos valores só retornaram aos limites de normalidade em 19 dias.

Em pacientes leucêmicos com infecção fúngica invasiva (candidíase disseminada e aspergilose pulmonar), ABLC substituiu AB-DOC após desenvolvimento de nefrotoxicidade e efeitos adversos relacionados à infusão. Dentre 10 pacientes incluídos neste estudo, todos restabeleceram as funções renais e 5 pacientes responderam completamente ao tratamento. AABLC foi administrada em dose máxima de $5 \mathrm{mg} / \mathrm{kg} /$ dia (Martino et al., 1999). Em outro estudo cinco pacientes leucêmicos, mas apresentando candidíase hepatoesplênica, foram tratados inicialmente com AB-DOC (concentração média total de 1,92 g). Após intolerância e toxicidade renal apresentada pela terapia, a ABLC foi adotada em $5 \mathrm{mg} / \mathrm{kg} / \mathrm{dia}$. A dose média total foi de $18,8 \mathrm{~g}$ e alguns efeitos adversos relacionados à infusão foram observados, mas nenhum paciente desenvolveu comprometimento renal durante a terapia com ABLC (Sallah et al., 1999). 
Merhav e Mieles (1997) observaram 65\% de resposta terapêutica em um grupo de pacientes transplantados utilizando ABLC, apesar de $46 \%$ de mortalidade. A justificativa dos autores para a alta mortalidade foi a falência de múltiplos órgãos associada ao quadro clínico dos pacientes. Apesar disto, a terapia com ABLC foi considerada segura e efetiva para infecções fúngicas nestes pacientes, devido ao baixo índice de toxicidade renal e aos efeitos adversos relacionados à infusão. Foi observada resistência in vitro de Candida glabrata e 3 pacientes responderam bem à infecção por Aspergillus spp.

Em recém-nascidos, Alder-Shohet, Waskin e Lieberman (2001) relataram a terapia com ABLC como segura e eficiente em 11 neonatos com infecção por Candida spp. Os pacientes foram intolerantes a AB-DOC devido a nefrotoxicidade e ABLC foi utilizada para promover a utilização de doses mais elevadas (3,9 $6,5 \mathrm{mg} / \mathrm{kg} / \mathrm{dia}$ ) e, portanto, mais efetivas.

\section{Estudos que avaliaram formulações tipo AB-lipossômica}

Além de AmBisome, outras formulações lipossômicas não produzidas industrialmente têm sido utilizadas como veículo de $\mathrm{AB}$ e suas diferenças são basicamente em termos de tamanho e composição lipídica. A maioria destas formulações foi propostas na década de 1990, mas algumas jamais chegaram a ensaios clínicos.

$A$ atividade de $A B$ veiculada a uma formulação lipossômica contendo um composto hidrofílico derivado de polietilenoglicol 1900 (PEG), colesterol e fosfatidilcolina de soja foi comparada por Van Etten et al. (1998) em relação a AmBisome e AB-DOC contra Candida albicans intracelular em macrófagos de peritôneo de camundongos. Observou-se que para a erradicação das leveduras foram necessárias concentrações elevadas de formulação lipossômica com derivado de PEG $(102,4 \mu \mathrm{g} / \mathrm{mL})$ e AmBisome $(51,2 \mu \mathrm{g} / \mathrm{mL})$, se comparada com $\mathrm{AB}-\mathrm{DOC}(0,8 \mu \mathrm{g} / \mathrm{mL})$, sem exposição prévia dos macrófagos por $\mathrm{AB}$.

Joly et al. (1992) avaliaram a atividade in vitro contra Candida albicans de $\mathrm{AB}$ veiculada em três tipos de lipossomas constituídos por três lipídeos diferentes (DPPC, DMPC e DSPC). As três formulações foram menos efetivas quando comparadas a AB-DOC, sendo que a formulação constituída por DSPC se apresentou mais eficiente que as demais. Segundo os autores, isto ocorreu devido ao fato de que $50 \%$ de $\mathrm{AB}$ não se apresentava encapsulada nesta formulação. Hopfer et al. (1984) relataram resultados semelhantes com lipossomas preparados com DMPC:DMPG. Desta forma, os autores propuseram que a necessidade de maior tempo de incubação influenciaria a atividade antifúngica devido à liberação da $\mathrm{AB}$ encapsulada.

\section{Estudos em animais}

Alguns autores propuseram o uso de AB-lipossômico (DMPC/DMPG 7:3) contendo anticorpo monoclonal antiC. albicans, tipo imunoglubolina $\mathrm{G}(\mathrm{IgG})$. Esta formulação foi comparada com AB-lipossômico sem IgG e AB-DOC no tratamento de candidíase sistêmica em camundongos normais por Hospenthal, Gretzinger e Rogers (1989) e em neutropênicos por Belay et al. (1993). O tratamento com AB-lipossoma-IgG aumentou o tempo de sobrevivência dos animais, mas mesmo com a dose mais elevada utilizada, $0,9 \mathrm{mg} / \mathrm{kg}$, ainda foram encontradas colônias de $C$. albicans em todos os animais. Outra observação interessante foi que a taxa de sobrevivência de animais tratados com as doses mais altas foi igual a dos que receberam $0,6 \mathrm{mg} / \mathrm{kg}$ (Belay, et al., 1993). Outro estudo foi realizado por Dromer et al. (1990) com anticorpo anti-C. neoformans, demonstrando aumento da sobrevida dos animais infectados. Anos mais tarde, Otsubo et al. (1998) relataram sucesso com o tratamento de aspergilose pulmonar em ratos com imunolipossoma de circulação prolongada. O anticorpo monoclonal utilizado reconhecia glicoproteínas que eram expressas nos vasos pulmonares, fazendo com que o lipossoma e, portanto, AB ligasse rapidamente no tecido pulmonar. Foi observado rápido decréscimo de $A$. fumigatus, elevando o índice terapêutico da formulação.

$\mathrm{O}$ uso de AB-lipossômico na forma de vesículas unilamelares pequenas constituído de dipalmitoilfosfatidilcolina (DPPC) protegeu as células tubulares renais de ratos contra a toxicidade de $\mathrm{AB}$, em doses convencionais $(1,5 \mathrm{mg} / \mathrm{kg})$, após injeções endovenosas repetidas. Entretanto, em doses mais elevadas, as alterações observadas foram semelhantes às obtidas com AB-DOC, ou seja, prejuízo da função tubular que progrediu com a repetição das administrações. As primeiras modificações induzidas por $\mathrm{AB}$ foram hipostenúria e poliúria (Longuet et al., 1991).

Em estudo anterior determinando a toxicidade aguda de doses baixas de AB-lipossômico em coelhos, não foram observadas alterações na taxa de filtração glomerular ou perda urinária de eletrólitos, mas foi relatada toxicidade tubular leve acompanhada de enzimúria. As concentrações de $\mathrm{AB}$ nos rins dos animais foram similares tanto para os tratados com AB-lipossômico quanto com AB-DOC, portanto o efeito protetor dos lipossomas não estava relacionado à alteração na farmacocinética do antifúngico, mas sim, à limitação da interação de $\mathrm{AB}$ com a membrana celular (Joly et al., 1989).

\section{Estudos em humanos}

Ralph, Barber e Grant (1991) administraram ABlipossômico constituído de $50 \mathrm{mg}$ de $\mathrm{AB} / \mathrm{dia}$ em vesículas multilamelares constituídas de DMPC e 
DMPG em razão de 7:3, em 4 pacientes para tratamento de candidíase no trato urinário. $O$ fármaco foi bem tolerado em todos os casos, mesmo sem medicação prévia para combater a toxicidade aguda. Não ocorreram efeitos tóxicos como hipocalemia, alterações hematológicas ou das enzimas hepáticas. As culturas tornaramse negativas de 1 a 4 dias, sugerindo que valores terapêuticos de $\mathrm{AB}$ na urina foram atingidos com doses convencionais através da formulação lipossômica. Estes achados tornam-se interessantes se compararmos com um dos primeiros estudos farmacocinéticos com AB-DOC em humanos, em que Atkinson e Bennett (1978) relataram excreção de apenas 3\% de AB.

A administração de AB-lipossômico na forma de pequenas vesículas unilamerales (lecitina de soja: colesterol, razão molar de 7:3), em doses de 0,1;0,4 e $1,0 \mathrm{mg} / \mathrm{kg}$ durante 3 dias, causou em alguns indivíduos tremores e febre moderados (Gokhale et al., 1993), similarmente ao relatado por Lopez-Berestein et al. (1985). Aumento dos valores séricos de uréia, creatinina e bilirrubina também foram observados, bem como hipocalemia, mas os autores atribuíram tais alterações ao estado debilitado e a outras doenças em curso (Gokhale et al., 1993).

A diminuição na habilidade em concentrar a urina, resultante de alterações induzidas por $\mathrm{AB}$ nas funções da alça de Henle, foi relatada experimentalmente (Kirsh et al., 1988) e em pacientes (Burgess, Birchall, 1972) sendo usualmente a primeira manifestação de toxicidade. A toxicidade tubular também foi detectada pela perda renal de sódio, potássio e fosfato. Não foi observado aumento dos valores plasmáticos de creatinina, mesmo em casos de toxicidade tubular aparente. Este fato não exclui a ocorrência de redução no índice de filtração glomerular, pois a perda de massa muscular devido à toxicidade sistêmica de $\mathrm{AB}$ poderia levar à subestimação de sua alteração (Longuet et al., 1991).

\section{Estudos que avaliaram $A B$ veiculada em emulsões lipídicas}

\section{Estudos in vitro e em animais}

A mistura de AB-DOC com emulsão para nutrição parenteral Intralipid ${ }^{\circledR} 20 \%$ (AB-DOC-IL) reduziu a toxicidade de $\mathrm{AB}$ in vitro sobre eritrócitos (Kirsh et al., 1988), células tubulares renais de cães (Lamb, Washington, Davis, 1990) e coelhos (Joly et al., 1994). O dano renal in vivo demonstrou a possibilidade de administrar doses superiores àquelas usadas com $\mathrm{AB}-\mathrm{DOC}$, permitindo que a dose máxima tolerada para camundongos fosse nove vezes maior com AB-DOC-IL (Kirsh et al., 1988), embora outro estudo tenha obtido valores inferiores (de 1,7 a 2,5 vezes) (Joly et al., 1994).

A atividade de AB foi mantida contra Candida albicans nos ensaios in vitro e in vivo utilizando coelhos infectados (Chavanet et al., 1992b) e contra infecção por Cryptococcus neoformans em camundongos (Joly et al., 1994). Além disso, em humanos, sua eficiência em candidíase oral foi similar à formulação convencional na mesma dosagem (Chavanet et al., 1992a).

\section{Estudos em humanos}

Algumas informações relacionadas à utilização de AB-DOC-IL no tratamento de infecções fúngicas graves em humanos foram publicadas na década de 1990. Macedo et al. (1994) relataram três casos de septicemia fúngica em pacientes profundamente granulocitopênicos cujo tratamento com tal preparação teve sucesso. Uma paciente de 9 anos de idade recebeu AB-DOC-IL $(0,6 \mathrm{mg}$ de $\mathrm{AB} / \mathrm{kg} / \mathrm{dia}$, infusão de 2 horas) para tratamento de infecção por Candida tropicalis e não foram relatados sinais de toxicidade renal (dose total de $12 \mathrm{mg} / \mathrm{kg}$ ). O mesmo esquema foi aplicado no tratamento de um menino com 2 anos, submetido a transplante de medula óssea para combater uma infecção por Candida albicans (dose total de $10 \mathrm{mg} / \mathrm{kg}$ ) e no tratamento de um homem com 65 anos infectado por Candida parapsilosis (dose total de $6,0 \mathrm{mg} / \mathrm{kg}$ ). Os efeitos tóxicos relacionados com a infusão de $\mathrm{AB}$ não foram avaliados, pois os pacientes estavam sob efeitos de anti-histamínicos, analgésicos e antipiréticos. Andrés, Limacher e Bergerat (1994) relataram o tratamento de aspergilose pulmonar em uma paciente imunodeprimida e granulocitopênica com $\mathrm{AB}$ DOC-IL (2,0 mg de AB/kg/dia, dose total de 2,0 g). Os efeitos tóxicos observados foram suaves e limitados à redução transitória da depuração de creatinina com azotemia e o aumento da excreção urinária de potássio, que regrediram com o final do tratamento. Em outro estudo, Leake, Appleyard e Hartley (1994) relataram o sucesso no tratamento de meningite criptocócica num paciente com AIDS utilizando AB-DOC-IL após nefrotoxicidade induzida por AB-DOC.

Os efeitos tóxicos induzidos por AB-DOC-IL também foram avaliados em estudos de triagem clínica. Foi relatada melhor tolerância clínica a $\mathrm{AB}$ com redução da ocorrência de toxicidade aguda como febre e calafrio (Chavanet et al., 1992a; Moreau et al., 1992), sendo que Caillot et al. (1994) verificaram incidência dez vezes menor desses efeitos comparando com mesmas doses da formulação preparada de forma convencional. O uso de emulsão não induziu aumento nos valores séricos de triglicérides e colesterol e os valores de sódio e potássio 
sofreram variações pouco significativas para os que receberam AB-DOC-IL (Chavanet et al., 1992a). Com relação à toxicidade renal, um estudo realizado por Moreau et al. (1992) demonstrou que $56 \%$ dos pacientes que receberam AB-DOC e apenas $12,5 \%$ dos que receberam AB-DOC-IL apresentaram nefrotoxicidade, sendo que a dose total administrada para o segundo grupo foi 1,6 vezes maior. Foi demonstrada diminuição de nefrotoxicidade com prevenção parcial no prejuízo da taxa de filtração glomerular (Caillot et al., 1994; Chavanet et al., 1992a). O aumento nos valores séricos de creatinina também foi maior em pacientes que receberam AB-DOC, (aumentos superiores a 75\%), totalizando mais de 50\% dos casos (Caillot et al., 1994).

Estudos mais recentes, comparando AB-DOC e AB-DOC-IL, têm sido realizados a fim de elucidar dados sobre a toxicidade, segurança e eficiência na veiculação de $\mathrm{AB}$ em emulsão lipídica. Nucci et al. (1999) relataram eficiência equivalente entre AB-DOC e AB-DOC-IL no tratamento empírico de pacientes com câncer, mas menor incidência de efeitos adversos relacionados à infusão nos que receberam AB-DOC-IL. Não foi observada diminuição relevante na ocorrência de nefrotoxicidade, pois 41 dos 56 pacientes tiveram complicações renais. Os efeitos de AB-DOC-IL na função renal também foram evidenciados por Schöffski et al. (1998), com aumento nos valores séricos de uréia e creatinina durante o tratamento. A terapia de $0,75 \mathrm{mg} / \mathrm{kg} /$ dia de $\mathrm{AB}$ associada à emulsão lipídica não foi recomendada pelos autores devido aos efeitos adversos, principalmente eventos tóxicos pulmonares.

O uso de AB-DOC-IL tornou-se uma opção de tratamento, principalmente devido ao custo frente às formulações lipídicas de AB. Para isso, dados quanto à estabilidade físico-química se fizeram necessários. Ranchère et al. (1996) relataram que o tamanho das partículas formadas por diferentes formas de preparações de AB-DOC-IL sofreu grandes mudanças após 5 horas de estocagem, com a conseqüente formação de precipitados de $\mathrm{AB}$. Por outro lado, Owens et al. (1997) demonstraram que AB era estável em $20 \%$ de emulsão lipídica e em $5 \%$ de dextrose por mais de 24 horas a $23-25^{\circ} \mathrm{C}$, o que foi determinado pela concentração final de AB (96\%).

\section{Farmacocinética e distribuição tecidual das formulações lipídicas de AB}

Padrões diferentes de biodistribuição foram observados entre as preparações lipídicas de AB. O texto a seguir faz relato aos estudos realizados com o intuito de comparar a farmacocinética das formulações de AB.
Collette et al. (1991) relataram o primeiro estudo de distribuição tecidual de $\mathrm{AB}$ em humanos utilizando vesículas unilamelares pequenas (lecitina de ovo:colesterol:estearilamina, $4: 3: 1$ ), nomeados "anfolipossomas", e demonstraram que a distribuição tecidual de $\mathrm{AB}$ não foi significativamente modificada em comparação com AB-DOC. A proporção do fármaco ligado aos tecidos, microbiologicamente inativa, foi similar para as ambas formulações, entretanto como doses maiores de anfolipossomas puderam ser administradas, altas concentrações séricas e tissulares permaneceram bioativas. A média de recuperação foi de 37,6\% recuperados de fígado, baço, rins, pulmões, coração, pâncreas, adrenais e cérebro. Em estudo anterior, tratando pacientes com AB-DOC, estes autores obtiveram recuperação tecidual da ordem de $38,8 \%$ da dose total administrada (Collette et al., 1989), valor similar também encontrado por Christiansen et al. (1985). Todos estes trabalhos relataram relação inversa entre recuperação e dose total, podendo, provavelmente, refletir baixa eluição de $\mathrm{AB}$ dos tecidos com eventual redistribuição e excreção. A excreção biliar também poderia ter significado importante, sendo estimada em 0,8-14,6\% após injeção diária de AB-DOC (Collette et al., 1989) e em 0,4-8,2\% após anfolipossoma (Collette et al. 1991).

Quando doses equivalentes de AmBisome ou ABDOC $(0,3 \mathrm{mg} / \mathrm{kg})$ foram administradas a camundongos (Proffitt et al., 1991), a encapsulação de AB resultou em concentrações aumentadas do antifúngico no sangue, fígado e baço. Gondal, Swartz e Rahman (1989) também relataram dados semelhantes. Em estudo anterior, esses autores, comparando ambas as formulações, verificaram altas concentrações de $\mathrm{AB}$ no fígado e baço para AmBisome, mas encontraram concentrações equivalentes nos rins e valores suavemente elevados nos pulmões. Em contraste, Van Etten et al. (1995) observaram concentrações diminuídas nos rins e pulmões, o que poderia explicar a baixa eficiência de AmBisome comparada com dose equivalente de $\mathrm{AB}-\mathrm{DOC}$ no tratamento de candidíase sistêmica em camundongo neutropênico (Van Etten et al., 1993). Também foi observado um tempo sangüíneo residente prolongado após administração de $7,0 \mathrm{mg} / \mathrm{kg}$ de AmBisome, pois a captação hepatoesplênica foi dependente da dose empregada. A biodistribuição das formulações não foi afetada pela imunocompetência ou infecção por C. albicans (Van Etten et al., 1995). Este perfil de distribuição foi similar em coelhos após injeção de AmBisome $(1,0 \mathrm{mg} / \mathrm{kg})$ e a concentração sérica máxima obtida foi 5 vezes maior que para AB-DOC (Lee et al., 1994).

Um estudo farmacocinético em pacientes neutropênicos conduzido por Walsh et al. (1998) avaliou AmBisome, revelando cinética não-linear. As concentra- 
ções plasmáticas e a área sobre a curva (AUC) aumentaram desproporcionalmente em relação às infusões. Observou-se captação acentuada pelos órgãos do SRE e o uso de administrações repetidas, que conseqüentemente produziram saturação do SRE, culminaram com concentrações plasmáticas elevadas. Bekersky et al. (2002), em estudo similar com voluntários saudáveis, relataram que as excreções urinária e fecal foram 10 vezes menores para AmBisome do que para AB-DOC e que o tempo de meiavida foi longo $\left(t_{1 / 2} 152 \mathrm{~h}\right)$. Além disso, a formulação lipossômica propiciou altas concentrações plasmáticas e baixo volume de distribuição aparente, sugerindo ser esta uma formulação que altera a farmacocinética de $\mathrm{AB}$, como um sistema de liberação controlada.

Heinemann et al. (1994), avaliando pacientes, compararam a farmacocinética de AB-DOC $(1,0 \mathrm{mg} / \mathrm{kg})$ com AB-DOC-IL (2,0 mg de AB/1,0 mL de Intralipid ${ }^{\circledR}$ $20 \%$ ) e com AmBisome (3,0 mg/kg). Os resultados mostraram diferenças entre as três formulações. A administração de AB-DOC-IL aumentou o volume de distribuição e conseqüentemente reduziu a concentração sérica máxima (39\%), evidenciando aumento de 2 vezes na depuração de $A B$, sugerindo captação pelo SRE. A farmacocinética de AmBisome também foi diferente de AB-DOC. O volume de distribuição foi quatro vezes menor, resultando em altas concentrações séricas de $\mathrm{AB}$ por tempo prolongado. Dessa forma, os valores de concentração sérica máxima foram 8 vezes maiores para AmBisome, levando a valores de depuração reduzidos pela metade. Outros estudos relataram resultados similares após a infusão de AB-DOC-IL, pois com esta mistura, as concentrações séricas de $\mathrm{AB}$ foram significativamente menores e a difusão do antifúngico foi mais rápida que para AB-DOC. (Chavanet et al., 1992a; Caillot et al., 1994).

Uma hora após a injeção endovenosa de ABLC $(1,0-10,0 \mathrm{mg} / \mathrm{kg})$ em camundongos e ratos, cerca de $48 \%$ da dose foi encontrada no fígado. A mesma dose de ABLC $(1,0 \mathrm{mg} / \mathrm{kg})$, quando comparada com AB-DOC, resultou em concentrações no fígado, baço e pulmão de 2 a 5 vezes maiores (Niki et al., 1990), mas nos rins, as concentrações foram suavemente maiores com AB-DOC (Clark et al., 1991). Os valores plasmáticos com ABLC foram bastante reduzidos, devido à rápida captação pelo sistema fagocítico mononuclear, resultando em valores sangüíneo menores que os atingidos com AB-DOC, e mesmo após doses consecutivas de $10 \mathrm{mg} / \mathrm{kg}$ a concentração sérica não ultrapassou 2,0 $\mu \mathrm{g} / \mathrm{mL}$ (Olsen et al., 1991). Estes experimentos foram compatíveis com os dados obtidos em humanos, pois a administração de ABLC $(0,1 ; 0,25$ e $0,5 \mathrm{mg} / \mathrm{kg}$ em três dias alternados) em voluntários saudáveis resultou em vo- lume de distribuição e depuração de $\mathrm{AB}$ aumentados em comparação com o grupo que recebeu $\mathrm{AB}-\mathrm{DOC}$, levando à diminuição da concentração sérica de $\mathrm{AB}$ (Kan et al., 1991).

A farmacocinética de ABLC em pacientes com infecções fúngicas sistêmicas foi avaliada por Adedoyin et al. (2000), que observaram rápida remoção de ABLC da circulação e alta distribuição entre os tecidos. ABLC produziu um rápido declínio logo após o pico plasmático e uma fase longa de eliminação.

Em voluntários saudáveis após dose única de $\mathrm{ABCD}$, foi demonstrado que o volume de distribuição aumentava com a dose, de 3,37 L/kg após a dose de $0,25 \mathrm{mg} / \mathrm{kg}$, para $7,92 \mathrm{~L} / \mathrm{kg}$ após $1,5 \mathrm{mg} / \mathrm{kg}$ (Sanders et al., 1991). Esses valores foram similares ao descrito para AB-DOC (Atkinson, Bennett, 1978), ocorrendo grandes modificações na concentração plasmática durante curtos períodos de tempo, sem grandes mudanças no perfil farmacocinético (Sanders et al., 1991). Entretanto, os resultados de estudo realizados com animais relataram diferenças entre ambas formulações. Segundo Fielding et al. (1991), após dose única de ABCD $(1,0$ e $5,0 \mathrm{mg} / \mathrm{kg})$ ou de AB-DOC $(1,0 \mathrm{mg} / \mathrm{kg})$ em ratos, os valores séricos de $\mathrm{ABCD}$ foram inferiores. Concentrações diminuídas foram encontradas em baço e pulmões, sendo observada redução de 3 a 7 vezes na concentração de $A B C D$ nos rins, mas no fígado os valores de $\mathrm{ABCD}$ foram 2 a 3 vezes maiores e cerca de $100 \%$ da $\mathrm{AB}$ administrada nessa formulação foram recuperados no fígado 30 minutos após a injeção. Resultados similares foram obtidos com cães, sendo que os valores de depuração foram aproximadamente 5 vezes maiores para $\mathrm{ABCD}$ e mais de $90 \%$ da dose administrada foi recuperada no fígado e baço após 16 dias (Fielding et al. 1992). Para os autores, o fígado estaria atuando como um reservatório da $\mathrm{AB}$ que não foi degradado rapidamente, pois cerca de $75 \%$ foram de $\mathrm{ABCD}$ foram recuperadas de forma intacta após 96 horas.

\section{ESTUDOS COMPARATIVOS DE EFICIÊNCIA TERAPÊUTICA ENTRE AS DIVERSAS FORMULAÇÕES}

As infecções fúngicas sistêmicas constituem a maior causa de morbi-mortalidade em pacientes imunocomprometidos e em pacientes imunocompetentes gravemente acometidos (Beck-Sague, Jarvis, 1993; Bodey, 1988). Em todo o mundo, Cryptococcus neoformans causa infecção grave em pacientes com linfopenia T CD4 decorrente de estágios avançados de HIV/AIDS. Histoplasma capsulatum, Coccidioides immitis e Penicillium marneffei causam infecções em áreas endêmicas e espécies de Candida e Aspergillus são os patógenos mais comuns em pacientes neutropênicos (Anaissie, 1992). 
A freqüência de infecções fúngicas oportunísticas em pacientes transplantados de medula óssea, doenças onco-hematológicas e tumores sólidos foi avaliada em estudo realizado na região sul brasileira, entre o período de janeiro de 2002 a maio de 2004. Dos 31 pacientes avaliados, $67,7 \%$ apresentavam infecção sistêmica por leveduras, sendo que $38,1 \%$ por Candida albicans seguido de Candida parapsilosis $(23,8 \%)$, Candida tropicalis $(14,4 \%)$, Candida krusei (9,5\%), Candida glabrata (9,5\%) e Geotrichum sp (4,7\%) (Aquino et al., 2004).

Entre 1998 a 2003, 10.348 microorganismos foram isolados de hemoculturas de pacientes ambulatoriais e hospitalares na região central brasileira, onde 3,31\% dos casos eram agentes micológicos (Vasconcellos, Mourão, Paiva, 2004). Os agentes fúngicos isolados foram Candida albicans $(35,27 \%)$, Candida parapsilosis $(27,69 \%)$, Candida tropicalis (16,61\%), Candida spp (14,86\%), Candida guilliermondii $(2,62 \%)$, Cryptococcus neoformans $(1,16 \%)$, Cryptococcus spp $(0,87 \%)$ e Torulopsis glabrata $(0,87 \%)$. Segundo os autores, observou-se ainda que a taxa de positividade de elementos fúngicos isolados aumentou consideravelmente nos últimos anos. Assim, em 1998, a média foi de 2,78\% enquanto que para o ano de 2003 foi de 4,23\%.

A terapêutica antifúngica das micoses sistêmicas não permite ainda obter cura clínica comparável às que se consegue com os antibióticos. O fato de muitas destas infecções surgirem em hospedeiros imunocomprometidos dificulta ainda mais a eficácia terapêutica. Algumas infecções fúngicas, como a aspergilose, são particularmente resistentes ao tratamento. Até agora, a anfotericina B (desoxicolato ou as formulações lipídicas) constitui a base da terapêutica das infecções fúngicas graves.

Embora as formulações lipídicas tenham demonstrado menor atividade em base de $\mathrm{mg} / \mathrm{kg}$, a diminuída toxicidade permitiu a administração de doses elevadas obtendo-se melhores resultados no tratamento e estimulando a utilização destas preparações em pacientes.

Um estudo retrospectivo analisando mais de 500 casos de pacientes idosos imunocomprometidos devido ao tratamento quimioterápico demonstrou a efetividade e segurança de ABLC no tratamento de infecção fúngica invasiva. Pequena incidência de toxicidade renal foi observada no grupo tratado com ABLC, se comparado com pacientes tratados com formulação convencional ABDOC, cuja concentração de creatinina sérica chegou a duplicar antes do final do tratamento. Os autores puderam demonstrar que ABLC e AB-DOC foram igualmente efetivos, mas que a formulação lipídica pareceu preservar a função renal (Hooshmand-Rad et al., 2005).

A preparação lipossômica AmBisome foi utilizada por pacientes transplantados no tratamento de micoses profundas causadas por espécies de Candida e Aspergillus. Neste estudo, Merhav et al. (2001) relataram $8 \%$ de ocorrência de infecção fúngica sistêmica entre 140 pacientes que sofreram transplantes de órgãos e AmBisome foi utilizado em todos os casos em concentração que variou de 1 a $5 \mathrm{mg} / \mathrm{kg} / \mathrm{dia}$. O tratamento mostrou-se efetivo e seguro, especialmente em relação aos efeitos colaterais, aliado à baixa mortalidade.

Um estudo clínico randomizado comparando a segurança e eficácia de duas formulações lipídicas de $\mathrm{AB}$ foi publicado por Wingard et al. (2000). Duzentos e quarenta e quatro pacientes neutropênicos e com estado febril constante foram tratados com AmBisome (3 ou $5 \mathrm{mg} / \mathrm{kg} / \mathrm{dia}$ ) ou ABLC ( $5 \mathrm{mg} / \mathrm{kg} / \mathrm{dia})$. O tratamento empírico foi bem sucedido em todos os grupos avaliados, mas os pacientes tratados com AmBisome apresentaram menos efeitos colaterais relacionados à infusão como febre, calafrios, tremores, além da significativa redução da incidência de nefrotoxicidade, se comparados aos pacientes tratados com ABLC. Em estudo mais recente, com 75 pacientes leucêmicos, comparando também AmBisome e ABLC, a resposta à terapia foi de $63 \%$ e $39 \%$ para ABLC e AmBisome, respectivamente. Os autores observaram que o grupo tratado com ABLC apresentou maior ocorrência de efeitos colaterais se comparado com o grupo tratado com a preparação lipossômica, mas este último grupo apresentou anormalidades na função hepática no final do tratamento (Fleming et al., 2001).

Cannon, Garey e Danziger (2001) compararam a ocorrência de nefrotoxicidade e a eficiência das formulações de AB em 67 pacientes entre 1996 e 1999. Os pacientes receberam AmBisome ou ABLC como tratamento para micoses sistêmicas. Os autores não observaram diferença significativa entre os dois grupos, tampouco diferença na ocorrência de nefrotoxicidade, considerada branda e verificada em $4 \%$ dos pacientes tratados com ABLC e $19 \%$ dos tratados com AmBisome.

Na tentativa de apontar a melhor formulação lipídica de $\mathrm{AB}$ no tratamento das fungemias, um estudo conduzido por Linder et al. (2003) teve como objetivo comparar a efetividade e a tolerabilidade de AB-DOC, AmBisome e ABDC no tratamento de infecção sistêmica por espécies de Candida em pacientes neonatos prematuros. Todos os pacientes receberam somente uma preparação até o final do tratamento, de acordo com a concentração sérica de creatinina $(\leq 1,2 \mathrm{mg} / \mathrm{dL}$ tratados com AB-DOC e $>1,2 \mathrm{mg} / \mathrm{dL}$ tratados com AmBisome ou ABCD). Não foi observada diferença na taxa de mortalidade entre os grupos, mas o índice de cura foi de $67,6 \%, 83,3 \%$ e $57,1 \%$ para ABDOC, AmBisome e ABDC respectivamente. 
As formulações lipídicas de $\mathrm{AB}$ parecem ser tão efetivas quanto $\mathrm{AB}-\mathrm{DOC}$ no tratamento de infecções fúngicas em pacientes imunocomprometidos febris, resultando em menor ocorrência de nefrotoxicidade e reações adversas relacionadas à infusão. Embora estas formulações representem alternativas atrativas de liberação de $\mathrm{AB}$ levando à menor toxicidade, o seu uso tem sido limitado a pacientes intolerantes à terapia convencional ou mesmo resistentes, devido ao alto custo em relação à terapia convencional. Uma análise farmacoeconômica descrita por Cagnoni et al. (2000) demonstrou que os custos hospitalares para tratamento de fungemias foram significativamente maiores para aqueles pacientes que receberam AmBisome como estratégia terapêutica. Enquanto que US\$16,60 foram necessários para custear $50 \mathrm{mg}$ de AB-DOC, US\$ 188,40 foram necessários para $50 \mathrm{mg}$ de AmBisome.

\section{MECANISMOS PROPOSTOS PARA REDUÇÃO DE TOXICIDADE}

A explicação para a diminuída toxicidade das formulações lipídicas de $\mathrm{AB}$ é razão de muitos estudos. A primeira teoria proposta teve como base a maior afinidade de $\mathrm{AB}$ por ergosterol que por colesterol (Bolard, 1986) e foi sustentada pela redução de toxicidade observada em eritrócitos com manutenção dos efeitos tóxicos para células de fungos (Juliano et al., 1986; Midez et al., 1989; Souza, et al., 1993). Assim, quando o antifúngico estivesse associado às formulações lipídicas, sua disponibilidade para células de mamíferos seria reduzida, permanecendo tóxica para células de fungos. Posteriormente, outra teoria levou em conta a possível alteração na disposição da $\mathrm{AB}$ internalizada no lipossoma, comparada àquela de AB-DOC. Estudos para determinação da distribuição tecidual e da depuração plasmática procuraram diferenças entre as formulações lipídicas eAB-DOC, na tentativa de explicar a diminuída toxicidade observada.

A distribuição de $\mathrm{AB}$ nos órgãos difere ao compararmos as várias formulações do antifúngico. Para ABLC, a $\mathrm{AB}$ atingiu altas concentrações no fígado, baço e pulmão dos animais e os valores plasmáticos permaneceram bastante reduzidos (Olsen et al., 1991). Já com ABCD, concentrações diminuídas foram encontradas em baço, pulmões e rins, mas no fígado os valores foram 2 a 3 vezes maiores e cerca de $100 \%$ da $\mathrm{AB}$ administrada nessa formulação foram recuperados no fígado 30 minutos após a injeção (Fielding et al., 1991). As concentrações de AB nos rins de animais foram similares tanto para tratados com AmBisome quanto com AB-DOC (Longuet et al., 1991). Não foi observada associação entre disposição alterada do antifúngico e redução de toxicidade, sendo que alguns autores não encontraram diferenças na distribuição de AmBisome e AB-DOC em vários órgãos (Szoka, Milholland, Edwards, 1987). Portanto, o efeito protetor das formulações lipídicas de $\mathrm{AB}$ não deve estar relacionado à alteração na farmacocinética do antifúngico e a proteção, possivelmente, deve ocorrer em nível celular, limitando a interação de $\mathrm{AB}$ com a membrana das células.

Um mecanismo de ação diferente para as formulações lipídicas de $\mathrm{AB}$ foi proposto, sugerindo a ocorrência de atividade antifúngica em macrófagos infectados por interação direta da $\mathrm{AB}$ com o microorganismo fagocitado. Desta forma, Legrand, Vertut-Doi e Bolard (1996) demonstraram, in vitro, a possível importância dos macrófagos fixos na farmacocinética da $\mathrm{AB}$. As formulações que propiciaram captação de baixas concentrações de $\mathrm{AB}$ pelos macrófagos in vitro, como AmBisome, foram as que apresentaram meia-vida in vivo maior do que $\mathrm{AB}$ DOC. As que promoveram extensiva captação de $A B$, semelhantes a ABLC e ABCD, foram encontradas em baixas concentrações na circulação. Assim, esses autores concluíram que a diminuição de toxicidade das formulações lipídicas de $\mathrm{AB}$, comparadas à $\mathrm{AB}-\mathrm{DOC}$, poderia ter ocorrido devido à possibilidade de o antifúngico ter sido internalizado como uma formulação lipídica e não na forma livre. A internalização variou muito entre as diferentes formulações lipídicas. $\mathrm{O}$ acúmulo de $\mathrm{AB}$ intracelular foi seguido por uma liberação do antifúngico para o meio extracelular na forma não ligada, que foi diferente dependendo do veículo utilizado, sugerindo que em alguns casos os macrófagos poderiam ser considerados como reservatórios do fármaco, liberando $\mathrm{AB}$ livre no meio.

Com base na captação de grandes concentrações de $\mathrm{ABCD}$ e $\mathrm{ABLC}$ pelo fígado, alguns autores propuseram que este órgão estaria atuando como um reservatório da $\mathrm{AB}$, que não foi degradada rapidamente (Fielding et al., 1991), de onde a AB seria lentamente liberada. Assim, como alta concentração de $\mathrm{AB}$ intacta foi recuperada do fígado após 48 horas da injeção de $\mathrm{ABCD}$, foi sugerido que, embora a captação pelo fígado fosse rápida, ela não teria sido submetida à extensiva metabolização, e após fagocitose pelos macrófagos do SRE poderia ser posteriormente liberada para a circulação (Legrand, VertutDoi, Bolard 1996). Estas deduções foram somadas a resultados de estudos que mostraram aumento da concentração circulante e da toxicidade de AmBisome em animais deficientes de PMN/macrófagos, induzindo a redução do índice terapêutico, em animais não deficientes destas células, a efetividade da formulação foi aumentada e a toxicidade diminuída, o que poderia ser explicado por aumento da captação do antifúngico pelos macrófagos dos tecidos infectados (Moonis, Ahmad, Bachhawar, 1994). 
Outros estudos avaliaram a interação de $\mathrm{AB}$ com lipoproteínas e mostraram que a alteração da composição lipídica vascular levou a redução dos efeitos tóxicos de AB-DOC (Wasan et al., 1993; Wasan et al., 1994; Chavanet et al., 1994; Marzzullo et al., 1996), na presença de lipoproteínas a forma livre de $\mathrm{AB}$ apresentou-se reduzida e sua concentração foi menor quando as lipoproteínas foram obtidas de soro pós-prandial, demonstrando que a dieta influenciou na quantidade de fármaco livre tóxico (Chavanet et al., 1994). Assim, a associação de AB com diferentes frações do plasma, assim como sua maior solubilização nestas frações, pode ser um fator responsável pela redução da toxicidade do antifúngico.

Wasan et al. (1993) realizaram diversos experimentos para elucidar a diminuída toxicidade de AmBisome em consideração à associação de $\mathrm{AB}$ com lipoproteínas. Seus resultados mostraram que modificações na temperatura e na composição lipídica do lipossoma implicaram alteração na distribuição da $\mathrm{AB}$ entre HDL e LDL. Após incubação de AB-DOC por 1 hora a $37{ }^{\circ} \mathrm{C}$ com soro humano, mais de $75 \%$ da $\mathrm{AB}$ foi recuperada na $\mathrm{HDL}$. Como a $\mathrm{AB}$ interage com colesterol, foi relatado que a proteína de transferência de lipídeos facilitou a transferência de $\mathrm{AB}$, mas não a de AmBisome, da HDL para a LDL, portanto os autores acreditaram que a diminuição de toxicidade estaria relacionada à distribuição predominante na HDL (Wasan et al., 1994) Além disso, a redução de toxicidade para células renais de porco LLC PK1 correlacionou com a diminuída expressão dos receptores para HDL encontrada nessas células (Wasan et al., 1994).

Na tentativa de aumentar o índice terapêutico de AB, vários grupos de pesquisadores em todo o mundo continuaram desenvolvendo estratégias para redução de toxicidade e manutenção do antifúngico mais efetivo para micoses sistêmicas já descrito.

Veiculou-se $\mathrm{AB}$ a uma emulsão lipídica rica em triglicérides (AB-emulsão), com colesterol na sua constituição e estabilizada por fosfatidilcolina de ovo. Estudos préclínicos foram realizados empregando-se $\mathrm{AB}$-emulsão com composição lipídica (70\% trioleína, $27 \%$ fosfatidilcolina e $3 \%$ colesterol) e metabolização similar a quilomícrons da linfa (Souza et al, 1993; Souza, Campa, 1999). Neste contexto, AB-emulsão foi desenvolvida e avaliada através de ensaios in vitro demonstrando redução da toxicidade em leucócitos PMN (Marzzullo, Souza, Campa, 1997) e em eritrócitos, bem como a manutenção da eficiência de $\mathrm{AB}$ contra Candida albicans (Souza et al., 1993). Estes resultados foram condizentes com estudos in vivo em que ratos e camundongos foram utilizados para avaliação histopatológica e farmacológica, observando-se redução dos efeitos tóxicos de AB (Souza, Saldiva, Campa, 2000). Assim, quando comparada AB-emulsão com a formulação comercial AB-DOC, demonstrou-se redução dos efeitos tóxicos in vitro (incubação com eritrócitos) e in vivo (administração em ratos) quando esta foi veiculada à emulsão (Souza et al., 1993). A redução de toxicidade de AB-emulsão nos rins foi avaliada por Souza, Saldiva e Campa (2000), que observaram menor dano renal para AB-emulsão, se comparada com AB-DOC, diferentemente das demais formulações lipídicas.

Otsubo et al. (1998) descreveram o desenvolvimento de um novo sistema de liberação para $\mathrm{AB}$. A formulação era constituída de óleo de soja purificado e lecitina de ovo, denominada nanosfera lipídica carreadora de AB. Os autores propuseram vários ensaios de caracterização das partículas, atividades in vitro e in vivo contra Aspergillus fumigatus e farmacocinética em ratos normais e imunocomprometidos. Quando comparada com AmBisome e AB-DOC, a nanosfera apresentou-se mais efetiva e menos tóxica contra aspergilose experimental, sugerindo ser esta nova formulação, um sistema de liberação de $\mathrm{AB}$ promissor. Um grupo de pesquisadores orientais desenvolveu uma formulação de $\mathrm{AB}$ semelhante. Também era constituída de óleo de soja e lecitina de ovo, mas com menor concentração de AB. Apesar disso, os estudos farmacocinéticos em ratos e cães demonstraram que a AUC foi maior para a nova formulação se comparada com AB-DOC, AmBisome, ABLC e ABCD. Os autores puderam concluir a manutenção da eficiência de $\mathrm{AB}$ incorporada a nanosfera, bem como a redução da toxicidade, se comparada às demais formulações (Fukui et al., 2003a,b,c).

Nos últimos 10 anos surgiram evidências de que o tratamento prévio de $\mathrm{AB}-\mathrm{DOC}$ por meio de aquecimento a $70{ }^{\circ} \mathrm{C}$ por 20 minutos, levaria à superagregação das partículas de $\mathrm{AB}$ e à drástica redução da toxicidade celular in vitro e in vivo (Gaboriau et al., 1997; Petit et al., 1998; Van Etten et al., 2000; Rogers et al., 2003). A toxicidade de AB depende da disponibilidade da molécula para as células do hospedeiro e sua atividade está relacionada à liberação do fármaco livre da formulação (Legrand et al., 1997). Outro aspecto importante é a alta afinidade de $A B$ por lipoproteínas plasmáticas, especialmente LDL, indicada como a mediadora da endocitose de $\mathrm{AB}$ em células do hospedeiro (Vertut-Doi, Ohnishi, Bolard, 1999). Com o aquecimento de AB-DOC, segundo os autores mais recentes, a AB estaria menos disponível para a ligação com lipoproteínas e explicaria a redução da citotoxicidade in vitro, redução da toxicidade in vivo e a manutenção da eficiência terapêutica, levando, portanto, ao aumento do índice terapêutico de AB-DOC. 


\section{CONCLUSÃO}

O índice terapêutico parece ter sido significativamente melhorado com as formulações lipídicas de $\mathrm{AB}$ e demais estratégias tecnológicas, permitindo o uso de doses elevadas com reduzida toxicidade renal. Como, em alguns estudos, as formulações lipídicas demonstraram-se menos ativas, seu índice terapêutico precisa ser testado clinicamente antes que seu uso possa ser recomendado apenas com base na redução de toxicidade. O surgimento das formulações lipídicas de $\mathrm{AB}$ é relativamente recente. Desta forma, poucos são os dados disponíveis quanto aos seus benefícios, limites e indicações. A importância dessas avaliações torna-se clara quando chegam a nosso conhecimento relatos de anafilaxia após administração de AmBisome em pacientes que não eram alérgicos a $\mathrm{AB}$ e também, a ocorrência de falha na prevenção de fungemia por C. glabrata com AmBisome, em que concentrações inferiores de $\mathrm{AB}-\mathrm{DOC}$ foram suficientes para controlar a infecção. Ambos os casos ocorreram com a formulação lipídica de AB mais amplamente estudada. Assim, essas formulações devem ser melhor investigadas com triagem clínica controlada, para averiguar se as formulações lipídicas melhoram a resposta clínica a infecções específicas comparadas com a formulação convencional, para determinar as doses apropriadas, a duração da terapia e se as taxas de sobrevivência podem ser melhoradas em pacientes imunocomprometidos com infecções invasivas.

\section{ABSTRACT \\ Therapeutic efficacy of amphotericin B lipid formulations}

Amphotericin B, discovered in 1953, has been the antifungal drug of choice for the most fungal infections in immonosupressed patients. Despite its toxicity and the introduction of new azolic antifungal agents in the 1980's, the therapeutic potencial, the spectrum of action, and almost 50 years of clinical experience, determine its efficacy for the treatment of fungal infections and secondary prophylaxis in neutropenic patients. Its efficacy has been challenged in every new antifungal drug presented for the scientists and doctors and, for this purpose, a wide range of new studies were performed in order to reduce its nephrotocixity. In addition to the necessity of establishing strong treatments with higher doses for systemic mycoses, the development of different ways of amphotericin $B$ delivery has been encouraged. Among on them, the entrapping amphotericin B into liposomes, the formation of lipid complex and colloidal dispersions produced successful results in reducing the tocixity and improving efficacy. Therefore, many studies demostrating new lipid preparations and delivery systems will be cited, focused on pharmacokinetics and mechanisms to improve the delivery of active drugs to sites of infections.

Uniterms: Amphotericin B. Lipid formulations. Liposomes. Lipid emulsions.

\section{REFERÊNCIAS BIBLIOGRÁFICAS}

ADEDOYIN, A.; SWENSON, C.; BOLCSAK, L.E.; HELLMANN, A.; RADOWSKA, D.; HORWITH, G.; JANOFF, A.S.; BRANCH, R.A. A pharmacokinetic study amphotericin B lipid complex injection (Abelcet) in patients with definite or probable systemic fungal infections. Antimicrob. Agents Chemother, v. 44, p. 2900-21902, 2000.

ADLER-MOORE, J.P.; CHIANG, S.; SATORIUS, A.; GUERRA, D.; McANDREWS, B.; McMANUS, E.J.; PROFFITT, R.T. Treatment of murine candidosis and cryptococcosis with a unilamellar liposomal amphotericin B formulation (AmBisome). J. Antimicrob. Chemother, v. 28, p. 63-71, 1991.

ALDER-SHOHET, F.; WASKIN, H.; LIEBERMAN, J.M. Amphotericin B lipid complex for neonatal invasive candidiasis. Arch. Dis. Child Fetal Neonatal, v. 84, p. 131-133, 2001.

AMATO, V.S.; NICODEMO, A.C.; AMATO, J.G.; BOULOS, M.; AMATO NETO, V. Mucocutaneous leishmaniasis associated with HIV infection trated successfully with liposomal amphotericin B (AmBisome). J. Antimicrob. Chemother., v. 46, p. 341342, 2000.

ANDRÈS, E.; LIMACHER, J.M.; BERGERAT, J.P. Pulmonary invasive aspergilosis: interest of a treatment with amphotericin B given in a triglyceridic emulsion. Rev. Méd. Interne, v. 15, p. 244-249, 1994.

ANNAISSIE, E. Opportunistic mycoses in the immunocompromised host: experience at a cancer center and review. Clin. Infect. Dis., v. 14, p. 43-53 1992.

ANNAISSIE, E.J.; MATTIUZZI, G.N.; MILLER, C.B.; NOSKIN, G.A.; GURWITH, M.J.; MAMELOK, R.D.; PIETRELLI, L.A. Treatment pf invasive fungal infections in renally impaired patients with amphotericin B colloidal dispersion. Antimicrob. Agents Chemother. v. 42, p. 606-611, 1998. 
AQUINO, V. R.; LUNARDI, L. W.; MACHADO, D. P.; PAIVA, R. M.; BARTH, A. L. Prevalência de fungos oportunistas em pacientes com neoplasias e doenças hematológicas no Hospital de Clínicas de Porto Alegre. In: CONGRESSO BRASILEIRO DE PATOLOGIA CLÍNICA/MEDICINA LABORATORIAL, 38, Florianópolis, 2004. Resumos. Florianópolis: Sociedade Brasileira de Patologia Clínica/Medicina Laboratorial, 2004. res. 521.

ARIKAN, S.; LOZANO-CHIU, M.; PAETZNICK, V.; NANGIA, S.; REX, J.H. Microdilution Susceptibility Testing of Amphotericin B, Itraconazole, and Voriconazole against Clinical Isolates of Aspergillus and Fusarium Species. J. Clin. Microbiol., v. 37, p. 3946-3951, 1999.

ASHER, I.M.; SCHURARTZMAN, G. Amphotericin B. Anal. Profiles Drug Subst., v. 6, p. 1-42, 1977.

ATKINSON, A.J.; BENNETT, J.E. Amphotericin B pharmacokinetics in humans. Antimicrob. Agents Chemother., v. 13, p. 271-276, 1978.

BALAKRISHNAN, A.R.; EASWARAN, K.R.F. CD and NMR studies on the aggregation of amphotericin B in solution. Biochim. Biophys. Acta., v. 1148, p. 269-277, 1993.

BALAKRISHNAN, A.R.; EASWARAN, K.R.K. Lipidamphotericin $\mathrm{B}$ complex structure in solution: a possible first step in the aggregation process in cell membranes. Biochemistry, v. 32, p. 4139-4144, 1993.

BARCHIESI, F.; SCHIMIZZI, A.M.; CASELLI, F.; NOVELLI, A.; FALLANI, S.; GIANNINI, D.; ARZENI, D.; CESARE, S.; FRANCESCO, L.F.; FORTUNA, M.; GIACOMETTI, A.; CARLE, A.; MAZZEI, T.; SCALISE, G. Interactions between triazoles and amphotericin B against Cryptococcus neoformans. Antimicrob. Agents Chemother., v. 44, p. 2435-2441, 2000.

BARTON, C.H.; PAHL, M.; VAZIRI, N.D. Renal magnesium wasting associated with amphotericin B therapy. Am. J. Med., v. 77, p. 471-474, 1984.

BECK-SAGUE, C.; JARVIS, W.R. Secular trends in the epidemiology of nosocomial fungal infections in the United States, 1980-1990. National Nosocomial Infections Surveillance System. J. Infect. Dis., v. 167, p. 1247-1251, 1993.

BEGGS, W.H. Physicochemical cell damage in relation to lethal amphotericin B action. Antimicrob. Agents Chemother., v. 38, p. 363-364, 1994.
BEKERSKY, I.; FIELDING, R.M.; DRESSLER, D.E.; LEE, J.W.; BUELL, D.N.; WALSH, T.J. Pharmacokinetics, excretion, and mass balance of liposomal amphotericin $\mathrm{B}$ (AmBisome) and Amphotericin B deoxycholate in humans. Antimicrob. Agents Chemother., v. 46, p. 828833, 2002.

BELAY, T.; HOSPENTHAL, D.R.; ROGERS, A.L.; PATTERSON, M.J. Treatment of systemic candidiasis in a neutropenic murine model using immunoglobulin $\mathrm{G}$ bearing liposomal amphotericin B. Mycopathologia, v. 123, p. 9-17, 1993.

BERNAUDIN, F.; HATHORN, J.; SCHAUFELE, R.; PIZZO, P.A. Effet in vitro de l'amphotéricine B sur le chimiotactisme des polynucléaires et des "large granular lymphocytes" à activité "natural killer". Pathol. Biol., v. 35, p. 1403-1407, 1987.

BHATHENA, D.B.; BULLOCK, W.E.; NUTTALL, C.E.; LUKE, R.G. The effects of amphotericin B therapy on the intrarenal vasculature and renal tubules in man. Clin. Nephrol., v. 9, p. 103-110, 1978.

BODEY, G.P. The emergence of fungi as major hospital pathogens. J. Hosp. Infect., v. 11, p. 411-426, 1988.

BOGGS, J.M.; CHANG, N.H.; GOUNDALKAR, A. Liposomal amphothericin B inhibits in vitro $\mathrm{T}$ lymphocyte response to antigen. Antimicrob. Agents Chemother, v. 35, p. 879-885, 1991.

BOLARD, J.; JOLY, V.; YENI, P. Mechanism of action of amphotericin B at the cellular level. It's modulation by delivery system. J. Liposome Res., v. 3, p. 409-427, 1993.

BOLARD, J.; LEGRAND, P.; HEITZ, F.; CYBULSKA, B. One-sided action of amphotericin B on cholesterolcontaining membranes is determined by its selfassociation in the medium. Biochemistry, v. 30, p. 5707$5715,1991$.

BOLARD, J.; SEIGNEURET, M.; BOUDET, G. Interaction between phospholipid bilayer membranes and the polyene antibiotic amphotericin B. Biochim. Biophys. Acta, v. 599, p. 280-293, 1980.

BORISOVA, M.P.; ERMINSHKIN, L.V.; SILBERSTEIN, A.Y. Mechanism of blockage of amphotericin $B$ channels in a lipid bilayer. Biochim. Biophys. Acta, v. 553, p. 450459, 1979. 
BOWDEN, R.A.; CAYS, M.; GOOLEY, T.; MAMELOK, R.D.; VAN BURIK, J.A. Phase I study of amphotericin $\mathrm{B}$ colloidal dispersion for the treatment of invasive fungal infections after marrow transplant. J. Infect. Dis., v. 173, p. 1208-1215, 1996.

BRAJTBURG, J.; ELBERG, S.; BOLARD, J.; KOBAYASHI, G.S.; LEVY, R.A.; OSTLUND, R.E.; SCHLESSINGER, D.; MEDOFF, G. Interaction of plasma proteins and lipoproteins with amphotericin B. $J$. Infect. Dis., v. 149, p. 986-997, 1984.

BRAJTBURG, J.; ELBERG, S.; KOBAYASHI, G.S.; BOLARD, J. Amphotericin B incorporated into egg lecithin-bile salt mixed micelles: molecular and cellular aspects relevant to therapeutic efficacy in experimental mycoses. Antimicrob. Agents Chemother., v. 38, n. 2, p. 300-306, 1994.

BRAJTBURG J.; ELBERG, S.; SCHWARTZ, D.R.; VERTUTCROQUIN, A.; SCHLESSINGER, D.; KOBAYASHI, G.S.; MEDOFF, G. Involvement of oxidative damage in erythrocyte lysis induced by amphotericin B. Antimicrob. Agents Chemother., v. 29, p. 172-176, 1985.

BURGESS, D.S.; HASTINGS, R.W.; SUMMERS, K.K.; HARDIN, T. C.; RINALDI, M.G. Pharmacodynamics of fluconazole, itraconazole, and amphotericin B against Candida albicans. Diagn. Microbiol. Infect. Dis., v. 36, p. 13-18, 2000.

BURGESS, J.L.; BIRCHALL, R. Nephrotoxicity of amphotericin B, with emphasis on changes in tubular function. Am. J. Med., v. 53, p. 77-84, 1972.

CAILLOT, D.; RENY, G.; SOLARY, E.; CASASNOVAS, O.; CHAVANET, P.; BONNOTTE, B.; PERELLO, L.; DUMAS, M.; ENTEZAM, F.; GUY, H. A controlled trial of the tolerance of amphotericin B infused in dextrose or in Intralipid in patients with haematological malignancies. J. Antimicrob. Chemother, v. 33, p. 603-613, 1994.

CANNON, J.P.; GAREY, K.W.; DANZIGER, L. D. A Prospective and Retrospective Analysis of the Nephrotoxicity and Efficacy of Lipid-Based Amphotericin B Formulations. Pharmacotherapy. v. 21, n. 9, p. 1107-1114, 2001.

CHAVANET, P.; CHARLIER, N.; BRENET, A.; GOUX, A.; MUGGÉO, E.; CAILLOT, D.; CASASNOVAS, O.; KISTERMANN, J.P.; WALDNER, A.; PORTIER, H. Émulsion de 1'amphotéricin B dans 1'intralipide 20\%: efficacité in vitro et in vivo. Pathol. Biol., v. 40, n. 5, p. 507-512, $1992 b$.
CHAVANET, P.; CHARLIER, N.; BRENET, A.; GOUX, A.; MUGGÉO, E.; CAILLOT, D.; CASASNOVAS, O.; KISTERMANN, J.P.; WALDNER, A.; PORTIER, H. Emulsion of amphotericin B in Intralipid 20\%: in vitro and iv vivo efficacy. Pathol. Biol., v. 40, p. 507-12, 1992b.

CHAVANET, P.Y.; GARRY, I.; CHARLIER, N.; CAILLOT, D.; KISTERMAN, J.P.; D’ATHIS, M.; PORTIER, H. Trial of glucose versus fat emulsion in preparation of amphotericin for use in HIV infected patients with candidiasis. $B M J$., v. 305, p. 921-925, 1992a.

CHEN, W.C.; BITTMAN, R. Kinetics of association of amphotericin B with vesicles. Biochemistry, v. 16, p. 4145-4149, 1977.

CHOPRA, R.; BLAIR, S.; STRANG, J.; CERVI, P.; PATTERSON, K.G.; GOLDSTONE, A.H. Liposomal amphotericin B (AmBisome) in the treatment of fungal infections in neutropenic patients. J. Antimicrob. Chemother., v. 28, p. 93-104, 1991.

CHRISTIANSEN, K.J.; BERNARD, E.M.; GOLD, J.W.M.; ARMSTRONG, D. Distribution and activity of amphotericin B in humans. J. Infect. Dis., v. 152, p. 10371043, 1985.

CLANCY, C.J.; NGUYEN, H. Correlation between in vitro susceptibility determined by E test and response to therapy with amphotericin B: results from a multicenter prospective study of candidemia. Antimicrob. Agents Chemother., v. 43, n. 5, p. 1289-1290, 1999.

CLARK, J.M.; WHITNEY, R.R.; OLSEN, S.J.; GEORGE, R.J.; SWERDEL, M.R.; KUNSELMAN, L.; BONNER, D.P. Amphotericin B lipid complex therapy of experimental fungal infections in mice. Antimicrob. Agents Chemother., v. 35, p. 615-621, 1991.

CLARK, S.B.; DERKSEN, A. Phosphatidylcholine composition of emulsions influences triacylglycerol lipolysis and clearance from plasma. Biochim. Biophys. Acta, v.13, p. 37-46,1987.

CLEMONS, K.V.; SOBEL, R.A.; WILLIAMS, P.L.; PAPPAGIANIS, D.; STEVENS, D.A. Efficacy of intravenous liposonal amphotericin B (AmBisome) against coccidioidal meningitis in rabbits. Antimicrob. Agents Chemother., v. 46, p. 2420-2426, 2002. 
CLEMONS, K.V.; STEVENS, D.A. Therapeutic efficacy of a liposomal formulation of amphotericin B (AmBisome) against murine blastomycosis. J. Antimicrob. Chemother., v. 32, p. 465-472, 1993.

COKER, R.J.; MURPHY, S.M.; HARRIS, J.R. Experience with liposomal amphotericin B (AmBisome) in cryptococcal meningitis in AIDS. J. Antimicrob. Chemother., v. 28, p. 105-109, 1991.

COLLETTE, N.; VAN der AUWERA, P.; MEUNIER, F.; LAMBERT, C.; SCULIER, J.P.; COUNE, A. Tissue distribution and bioactivity of amphotericin $\mathrm{B}$ administered in liposomes to cancer patients. $J$. Antimicrob. Chemother., v. 21, p. 535-548, 1991.

CRAVEN, P.C.; GREMILLION, D.H. Risk factors of ventricular fibrillation during rapid amphotericin $\mathrm{B}$ infusion. Antimicrob. Agents Chemother., v. 27, p. 868$871,1985$.

CROFT, S.L.; DAVIDSON, R.N.; THORNTON, E.A. Liposomal amphotericin $\mathrm{B}$ in the treatment of visceral leishmaniasis. J. Antimicrob. Chemother., v. 28, suppl.B, p. 111-8, 1991.

CYBULSKA, B.; HERVE, M.; BOROWSKI, E.; GARYBOBO, C.M. Effect of the polar head structure of polyene macrolide antifungal antibiotics on the mode of permeabilization of ergosterol-and cholesterolcontaining lipidic vesicles studied by 31P-NMR. Mol. Pharmacol., v. 29, p. 293-298, 1985.

DAVEY, K.G.; HOLMES, A.D.; JOHNSON, E.M.; SZEKELY, A.; WARNOCK, D.W. Comparative evaluation of FUNGITEST and broth microdilution methods for antifungal drug susceptibility testing of Candida species and Cryptococcus neoformans. J. Clin. Microbiol., v. 36, p. 926-930, 1998.

DAVIDSON, R.N.; CROFT, S.L.; SCOTT, A.; MAINI, M.; MOODY, A.H.; BRYCESON, A.D.M. Liposomal amphotericin B in drug-resistant visceral leishmaniasis. Lancet, v. 337, p. 1061-1062, 1991.

DIETZE, R.; MILAN, E.P.; BERMAN, J.D.; GROGL, M.; FALQUETO, A.; FEITOSA, T.F.; LUZ, K.G.; SUASSUNA, F.A.B.; MARINHO, L.A.C.; KSIONSKI, G. Treatment of brazilian kala-azar with a short course of Amphocil (amphotericin B cholesterol dispersion). Clin. Infect. Dis., v. 17, p. 981-986, 1993.
DISMUKES, W.E. Introdution to antifungical drugs. Clin. Infect. Dis., v. 30, p. 653-657, 2000.

DRISCOLL, D.F.; BHARGAVA, H.N.; LI, L.; ZAIM, R.H.; BABAYAN, V.K.; BISTRIAN, B.R.; Physicochemical stability of total nutrient admixtures. Am. J. Health-Syst. Pharm., v. 52, p. 623-634, 1995.

DROMER, F.; BARBET, J.; BOLARD, J.; CHARREIRE, J.; YENI, P. Improvement of amphotericin B activity during experimental cryptococcosis by incorporation into specific immunoliposomes. Antimicrob. Agents Chemother., v. 34, p. 2055-2060, 1990.

DRUMMOND, D.C.; WONG, C.W.; WHITMAN, L.M.; McCORMACK, J.G. The effects of amphotericin B, fluconazole and miconazole on neutrophil and lymphocyte function in a guinea pig model. $J$. Antimicrob. Chemother, v. 36, p. 375-384, 1995.

DURAND, R.; PAUL, M.; PRATLONG, RIVOLLET, D.; DUBREUIL-LEMAIRE, M.; HOUIN, R.; ASTIER, A.; DENIAU, M. Leishmania infantum: lack of parasite resistance to amphotericin B in a clinically resistant visceral leishmaniasis. Antimicrob. Agents Chemother., v. 42, n. 8, p. 2141-2143, 1998.

ELDEM, T., ARICAN-CELLAT, N., AGABEYOGLU, I., AKOVA, M., KANSU, E. Pharmacokinetics of liposomal amphotericin B in neutropenic cancer patients. Int. J. Pharm., v. 213, p. 153-161, 2001.

ESPINEL-INGROFF, A.; BARTLETT, M.; BOWDEN, R.; CHIN,N.X.; COOPER, J.R.; FOTHERGILL, A.; MCGINNIS, M.R.; MENEZES, P.; MESSER, S.A.; NELSON, P.W.; ODDS, F.C.; PASARELL, PETER, J.; PFALLER, M.A.; REX, L.H.; RINALDI, M.G.; SHANKLAND, G.S.; WALSH, T.J.; WEITZMAN, I. Multicenter evaluation of proposed standardized procedure for antifungal susceptibility testing of filamentous fungi. J. Clin. Microbiol., v. 35, p. 139143, 1997.

FIELDING, R.M.; SINGER, A.W.; WANG, L.H.; BABBAR, S.; GUO, L.S.S. Relationship of pharmacokinetics and drug distribution in tissue to increased safety of amphotericin B colloidal dispersion in dogs. Antimicrob. Agents Chemother., v. 36, p. 299-307, 1992. 
FIELDING, R.M.; SMITH, P.C.; WANG, L.H.; PORTER, J.; GUO, L.S.S. Comparative pharmacokinetics of amphotericin B after administration of a novel colloidal delivery system, $\mathrm{ABCD}$, and a conventional formulation to rats. Antimicrob. Agents Chemother., v. 35, p. 12081213, 1991.

FISHER, N.C.; SINGUAL, S.; MILLER, S.J.; HASTING, J.G.M.; MUTIMER, D.J. Fungal infection and liposonal amphoericin B (AmBisome) therapy in liver transplantation: a 2 year review. J. Antimicrob. Chemother., v. 43, p. 597-600, 1999.

FLEMING, R.V.; KANTARJIAN, H.M., HUSNI, R.; ROLSTON, K.; LIM, J.; RAAD, I.; PIERCE, S.; CORTES, J.; ESTEY, E. Comparison of amphotericin B lipid complex (ABLC) vs. ambisome in the treatment of suspected or documented fungal infections in patients with leukemia. Leuk Lymphoma., v. 40, p. 511-520, 2001.

FORSTER, D.; WASHINGTON, C.; DAVIS, S.S. Toxicity of solubilized and colloidal amphotericin B formulations to human erythrocytes. J. Pharm. Pharmacol., v. 40, p. 325-328, 1988.

GANIS, P.; AUITABILE, G.; MECHLINKI, W.; SCHAFFNER, C.P. Polyene macrolide antibiotic amphotericin B. Crystal structure of the N-iodo-acetyl derivative. J. Amer. Chem. Soc., v. 93, p. 4560-4564, 1971.

GARCIA, A.; ADLER-MOORE, J.P.; PROFFITT, R. Single-dose AmBisome (lipossomal amphotericin B) as prophylaxis for murine systemic candidiasis and histoplasmosis. Antimicrob. Agents Chemother., v. 44, p. 2327-2332, 2000.

GARCIA, A.; ADLER-MOORE, J.P.; PROFFITT, R. Single-dose AmBisome (lipossomal amphotericin B) as prophylaxis for murine systemic candidiasis and histoplasmosis. Antimicrob. Agents Chemother, v. 44, p. 2327-2332, 2000.

GERBAUD, E.; TAMION, F.; GIRAULT, C.; CLABAULT, K.; LEPRETRE, S.; LEROY, J.; BONMARCHAND, G. Persistent acute tubular toxicity after switch from conventional amphotericin B to liposomal amphotericin B (AmBisome). J. Antimicrob. Chemother, v. 51, p. 473475, 2003.
GERKENS, J.F.; BRANCH, R.A. The influence of sodium status and furosemide on canine acute amphotericin B nephrotoxicity. J. Pharmacol. Exp. Ther., v. 214, p. 306$311,1980$.

GOKHALE, P.C.; BARAPATRE, R.J.; ADVANI, S.H.; KSHIRSAGAR, M.A.; PANDYA, S.K. Pharmacokinetics and tolerance of liposomal amphotericin B in patients. $J$. Antimicrob. Chemother, v. 32, p. 133-139, 1993.

GOLD, N.; STOUT, H.A.; PAGANO, J.F.; DONOVICK, R. Amphotericin A and B, antifungal antibiotics produced by a streptomycete. I. In vivo studies. Antibiot. Annu., v. 1955-1956, p. 579-586, 1956.

GONDAL, J.A.; SWARTZ, R.P.; RAHMAN, A. Therapeutic evaluation of free and liposome-encapsulated amphotericin $\mathrm{B}$ in the treatment of systemic candidiasis in mice. Antimicrob. Agents Chemother., v. 33, p. 1544-1548, 1989. GONZALES, C.A.; SCOTT, I.U.; CHAUDHRY, N.A.; LUU, K.M.; MILLER, D.; MURRAY, T.G; DAVIS, J.L. Endogenous endophthalmitis caused by Histoplasma capsulatum var. capsulatum. A case report and a literature review. Ophthalmology, v. 107, p. 725-729, 2000.

GRAYBILI, J.R.; BOCANEGRA, R. Liposomal amphotericin B therapy of murine histoplasmosis. Antimicrob. Agents Chemother., v. 39, p. 1885-1887, 1995.

GROLL, A.H.; MICKIENE, D.; PISCITELLI, S.C.; WALSH, T.J. Distribution of lipid formulations of amphotericin B into bone marrow and fat tissue in rabbits. Antimicrob. Agents Chemother., v. 44, p. 408410, 2000.

HAHN, R.C.; HAMDAN, J.S. Effects of amphotericin B and three azole derivatives on the lipids of yeast cells of Paracoccidioides brasiliensis. Antimicrob. Agents Chemother., v. 44, p. 1997-2000, 2000.

HANSON, L.H.; STEVENS, D.A. Comparison of antifungal activity of amphotericin $\mathrm{B}$ deoxycholate suspension with that of amphotericin B cholesteryl sulfate colloidal dispersion. Antimicrob. Agents Chemother., v. 36, p. 486488, 1992.

HEDEMAN, H.; BRONDSTED, H.; MULLERTZ, A.; FROKJAER, S. Fat emulsions based on structured lipids (1,3-specific triglycerides): an investigation of the in vivo fate. Pharm. Res., v. 13, p. 725-780,1996. 
HEIDEMANN, H.T.H.; GERKENS, J.F.; SPICKARD, W.A.; JACKSON, E.K.; BRANCH, R.A. Amphotericin B nephrotoxicity in humans decreased by salt repletion. Am. J. Med., v. 75, p. 476-81, 1983.

HEINEMANN, V.; BOSSE, D.; DEBUS, J.A.; WACHHOLZ, K.; FORST, H.; WILMANNS, W. Enhanced pulmonary accumulation of liposomal amphotericin B (AmBisome) in acute liver transplant failure. J. Antimicrob. Chemother., v. 40, p. 295-297, 1997.

HOOSHMAND-RAD, R.; CHU, A.; GOTZ, V.; MORRIS, J.; BATTY, S.; FREIFELD, A. Use of amphotericin B lipid complex in elderly patients. J. Infection., v. 50, p. 277-287, 2005.

HOPFER, R.L.; MILLS, K.; MEHTA, R.; LOPEZBERESTEIN, G.; FAINSTEIN, V.; JULIANO, R.L. In vitro antifungal activities of amphotericin $\mathrm{B}$ and liposome-encapsulated amphotericin B. Antimicrob. Agents Chemother., v. 25, p. 387-389, 1984.

HOPFER, R.L; MEHTA, R.; LOPEZ-BERESTEIN, G. Synergistic antifungal activity and reduced toxicity of liposomal amphotericin B combined with gramicidin $\mathrm{S}$ or NF. Antimicrob. Agents Chemother., v. 31, p. 19781981, 1987.

HOSPENTHAL, D.; GRETZINGER, K.; ROGERS, A. Treatment of a murine model of systemic candidiasis with liposomal amphotericin B bearing antibody to Candida albicans. J. Med. Microbiol., v. 30, p. 193-197, 1989.

HOSPENTHAL, D.R.; ROGERS, A.L.; MILLS, G.L. Development of amphotericin B liposomes bearing antibody specific to Candida albicans. Mycopathologia, v. 110 , p. $37-45,1988$.

HUANG, W.; ZHANG, Z.; HAN, X.; TANG, J.; WANG, J. DONG, S.; WANG, E. Ion channel behavior of amphotericin B in sterol-free and cholesterol- or ergosterol- containing supported bilayer model membranes investigated by electrochemistry and spectroscopy. Biophys. J., v. 83, p. 3245-3255, 2002.

HUDSON, J.; SCOTT, G.L.; WARNOCK, D.W. Treatment of hepatic candidosis with liposomal amphotericin B in patient with acute leukaemia. Lancet, v. 338, p. 1534$1535,1991$.
JANOFF, A.S.; BONI, L.T.; POPESCU, M.C.; MINCHEY, S.R.; CULLIS, P.R.; MADDEN, T.D.; TARASCHI, T.; GRUNER, S.M.; SHYAMSUNDER, E.; TATE, M.W.; MENDELSOHN, R.; BONNER, D. Unusual lipid structures selectively reduce the toxicity of amphotericin B. Proc. Natl. Acad. Sci., v. 85, p. 6122-6126, 1988.

JOLY, V.; BOLARD, J.; SAINT-JULIEN, L.; CARBON, C.; YENI, P. Influence of phospholipid/amphotericin B ratio and phospholipid type on in vitro renal cell toxicities and fungicidal activities of lipid-associated amphotericin B formulations. Antimicrob. Agents Chemother., v. 36, p. 262-266, 1992.

JOLY, V.; DROMER, F.; BARGE, J.; YENI, P.; SETA, N.; MOLAS, G.; CARBON, C. Incorporation of amphotericin B (AMB) into liposomes alters AMBinduced acute nephrotoxicity in rabbits. J. Pharmacol. Exp. Ther., v. 251, p. 311-316, 1989.

JOLY, V.; FARINOTTI, R.; SAINT-JULIEN, L.; CHÉRON, M.; CARBON, C.; YENI, P. In vitro renal toxicity and in vivo therapeutic efficacy in experimental murine cryptococcosis of amphotericin B (Fungizone) associated with Intralipid. Antimicrob. Agents Chemother., v. 38, p. 177-183, 1994.

JULLIÈN, S.; BRAJTBURG, J.; BOLARD, J. Affinity of amphotericin $\mathrm{B}$ for phosphatidylcholine vesicles as a determinant of the in vitro cellular toxicity of liposomal preparations. Biochim. Biophys. Acta., v. 1021, p. 39-45, 1990.

JULLIEN, S.; CAPUOZZO, E.; SALERNO, C.; CRIFÒ, C. Effects of polyene antibiotics on the activation of human polymorphonuclear leukocytes. Biochem. Pharmacol., v. 41, p. 2037-2040, 1991.

KAN, V.L.; BENNETT, J.E.; AMANTEA, M.A.; SMOLSKIS, M.C.; MCMANUS, E.; GRASELA, D.M.; SHERMAN, J.W. Comparative safety, tolerance, and pharmacokinetics of amphotericin B lipid complex and amphotericin B desoxycholate in healthy male volunteers. J. Infect. Dis., v. 164, p. 418$421,1991$.

KASUMOV, K.M.; BORISOVA, M.P.; ERMISHKIN, L.N.; POTSELUYEV, V.M.; SILBERSTEIN, A.Y.; VAINSHTEIN, V.A. How do ionic channel properties depend on the structure of polyene antibiotic molecules? Biochim. Biophys. Acta, v. 551, p. 229-237, 1979. 
KIRSH, R.; GOLDSTEIN, R.; TARLOFF, J.; PARRIS, D.; HOOK, J.; HANNA, N.; BUGELSKI, P.; POSTE, G. An emulsion formulation of amphotericin $\mathrm{B}$ improves the therapeutic index when treating systemic murine candidiasis. J. Infect. Dis., v. 158, p. 1065-1070, 1988.

KLASTERSKY, J. Empirical Antifungal Therapy. Int. J. Antimicr. Agents, v. 23, p. 105-112, 2004.

LAING, R.B.S.; MILNE, L.J.R.; LEEN, C.L.S.; MALCOM, G.P.; STEERS, A.J.W. Anaphylactic reactions to liposomal amphotericin. Lancet, v. 344, p. 682,1994.

LAMB, K.A.; WASHINGTON, C.; DAVIS, S.S. Toxicity of amphotericin B emulsion to cultured canine kidney cell monolayers. J. Pharm. Pharmacol., v. 43, p. 522-524, 1990.

LAMPO, N.; SPILIOPOULOS, A.; LICKER, M.; TSCHOPP, J.M. Management of postpneumonectomy Aspergillus empyema extending into the thoracic wall: a plea for radical surgery and caution when using lipossomal amphotericin B. Inter. Cardiovasc. Thoracic Surg., v. 2, p. 682-684, 2003.

LAMY-FREUND, T.M.; SCHREIER, S.; PEITZSCH, R.M.; REED, W.F. Characterization and time dependence of amphotericin B: deoxycholate aggregation by quasielastic light scattering. J. Pharm. Sci., v. 80, n. 3, p. 262-266, 1991.

LEAKE, H.A.; APPLEYARD, M.N.; HARTLEY, J.P.R. Successful treatment of resistant cryptococcal meningitis with amphotericin B lipid emulsion after nephrotoxicity with conventional intravenous amphotericin B. J. Infect., v. 28, p. 319-322, 1994.

LEE, J.W.; AMANTEA, M.A.; FRANCIS, P.A.; NAVARRO, E.E.; BACHER, J.; PIZZO, P.A.; WALSH, T.J. Pharmacokinetics and safety of a unilamellar liposomal formulation of amphotericin B (AmBisome) in rabbits. Antimicrob. Agents Chemother, v. 38, n. 4, p. 713-718, 1994.

LEENDERS, A.C.A.P.; MARIE, S.; KATE, M.T.; BAKKER-WOUDENBERG, I.A.J.M.; VERBRUGH, H.A. Liposomal amphotericin B (AmBisome) reduces dissemination of infection as compared with amphotericin B deoxycholate (Fungizone) in a rat model of pulmonary aspergillosis. J. Antimicrob. Chemother., v. 38, p. 215-225, 1997.
LEGRAND, P.; ROMERO, E.A.; COHEN, B.E.; BOLARD, J. Effects of aggregation and solvent on the toxicity of amphotericin B to human erythrocytes. Antimicrob. Agents Chemother., v. 36, n. 11, p. 2518-2522, 1992.

LEQUAGLIE, C. Liposomal amphotericin B (AmBisome): efficacy and safety of low-dose therapy in pulmonary fungal infections. J. Antimicrob. Chemother, v. 49, p. 4950, 2002.

LI, R.; CIBLAK, M.A.; NORDOFF, N.; PASARELL, L.; WARNOCK, D.W.; MCGINNIS, M.R. In vitro activities of voriconazole, itraconazole, and amphotericin B against Blastomyces dermatitidis, Coccidioides immitis, and Histoplasma capsulatum. Antimicrob. Agents Chemother., v. 44, p. 1734-1736, 2000.

LINDER, N.; KLINGER, G.; SHALIT, I.; LEVY, I.; ASHKENAZI, S.; HASKI, S.; LEVIT, O.; SIROTA, L. Treatment of candidaemia in premature infants: comparison of three amphotericin B preparations. $J$. Antimicrob. Chemother, v. 52, p. 663-669, 2003.

LONGUET, P.; JOLY, V.; AMIRAULT, P.; SETA, N.; CARBON, C.; YENI, P. Limited protection by small unilamellar liposomes against the renal tubular toxicity induced by repeated amphotericin B infusions in rats. Antimicrob. Agents Chemother, v. 35, p. 1303-1308, 1991.

LOPEZ-BERESTEIN, G.; BODEY, G.P.; FRANKEL, L.S.; MEHTA, K. Treatment of hepatosplenic candidiasis with liposomal-amphotericin B. J. Clin. Oncol., v. 5, p. 310317, 1987.

LOPEZ-BERESTEIN, G.; FAINSTEIN, V.; HOPFER, R.; MEHTA, K.; SULLIVAN, M.P.; KEATING, M.; ROSENBLUM, M.G.; MEHTA, R.; LUNA, M.; HERSH, E.M.; REUBEN, J.; JULIANO, R.L.; BODEY, G.P. Liposomal amphotericin B for the treatment of systemic fungal infections in patients with cancer: a preliminary study. J. Infect. Dis., v. 151, p. 704-710, 1985.

LOPEZ-BERESTEIN, G.; MEHTA, R.; HOPFER, R.L.; MILLS, K.; KASI, L.; MEHTA, K.; FAINSTEIN, V.; LUNA, M.; HERSH, E.M.; JULIANO, R. Treatment and prophylaxis of disseminated infection due to Candida albicans in mice with liposome-encapsulated amphotericin B. J. Infect. Dis., v. 147, p. 939-945, 1983. 
MACEDO, M.C.M.A.; DULLEY, F.L.; OSTRONOFF, M.; MACHADO, C.M.; ZAMBON, E.; MATSUMOTO, C.; DORLHIAC-LLACCER, P.; CHAMONE, D.F. Effectiveness of amphotericin B in lipid emulsion for treating fungal septicemia in granulocytopenic patients. Clin. Infect. Dis., v. 19, p. 366-367, 1994.

MARTINO, R.; SUBIRÁ, M.; SURED, A.; SIERRA, J. Amphotericin B lipid complex at $3 \mathrm{mg} / \mathrm{kg} /$ day for treatment of invasive fungal infections in adults with haematological malignancies. J. Antimicrob. Chemother., v. 44, p. 569-572, 1999.

MARZZULLO, L.; SOUZA, L.C.; CAMPA, A. Effect of amphotericin $\mathrm{B}$ associated with a lipid emulsion on the oxidative burst of human polymorphonuclear leukocytes. Gen. Pharmacol., v. 27, p. 203-207, 1997.

MBONGO, N.; LOISEAU, P.M.; BILLION, M.A.; ROBERT-GERO, M. Mechanism of amphotericin B resistance in Leishmania donavani promastigotes. Antimicrob. Agents Chemother, v. 42, n. 2, p. 352-357, 1998.

MERHAV, H.; MIELES, L. Amphotericin B lipid complex in the treatment of invasive fungal infections in liver transplant patiens. Transpl. Proceed., v. 29, p. 2670-2674, 1997.

MERHAV, H.; NAKACHE, R.; HOURI, I.; ORNIWASSERLAUF, R. Liposomal amphotericin B (AmBisome) is safe and effective in the treatment of invasive mycosis in organ transplant patients. Transpl. Proceed., v. 33, p. 2937-2938, 2001.

MILLS, W.; CHOPRA, R.; LINCH, D.C.; GOLDSTONE, A.H. Liposomal amphotericin B in the treatment of fungal infections in neutropenic patients: a single-center experience of 133 episodes in 116 patients. Br. $J$. Haematol., v. 86, p. 754-760, 1994.

MIYAZAKI, T.; KOHNO, S.; YASUOKA, A.; MAESAKI, S.; YAMADA, H.; SASAYAMA, K.; DOHTSU, Y.; YAMAGUCHI, K.; HIROTA, M. A lipid emulsion formulation of amphotericin B for the treatment of murine candidiasis and cryptococcosis. Chemotherapy, v. 38, p. 548-551, 1990.

MOONIS, M.; AHMAD, I.; BACHHAWAT, B.K. Effect of elimination of phagocytic cells by liposomal dichloromethylene diphosphonate on aspergillosis virulence and toxicity of liposomal amphotericin B in mice. Antimicrob. Agents Chemother., v. 33, p. 571-583, 1994.
MORA-DUARTE, J.; BETTS, R.; ROTSTEIN, C.; COLOMBO, A.L.; THOMPSON-MOYA, L.; SMIETANA, J.; LUPINACCI, R.; SABLE, C.; KARTSONIS, N.; PERFECT, J. Comparison of caspofungin and amphotericin $\mathrm{B}$ for invasive candidiasis. NEJM, v. 347, n. 25, p 2020-2029, 2002.

MOREAU, P.; MILPIED, N.; FAYETTE, N.; RAMÉE, J.F.; HAROUSSEAU, J.L. Reduced renal toxicity and improved clinical tolerance of amphotericin B mixed with Intralipid compared with conventional amphotericin $\mathrm{B}$ in neutropenic patients. J. Antimicrob. Chemother., v. 30, p. 535-541, 1992.

MORIBE, K.; MARUYAMA, K.; IWATSURU, M. Molecular localization and state of amphotericin B in PEG liposomes. Int. J. Pharm., v. 193, p. 97-106, 1999.

NUCCI, M.; LOUREIRO, M.; SILVEIRA, F.; CASALL, A.R.; BOUZAS, L.F.; VELASCO, E.; SPECTOR, N.; PULCHERI, W. Comparison of the toxicity of amphotericin B in 5\% dextrose with that of amphotericin $B$ in fat emulsion in a randomized trial with cancer patients. Antimicrob. Agents Chemother., v. 43,p. 1445-1448, 1999.

OAKLEY, K.L.; MOORE, C.B.; DENNING, D.W. In vitro activity of SCH-56592 and comparison with activities of amphotericin B and itraconazole against Aspergillus spp. Antimicrob. Agents Chemother., v. 41, p. 1124-1126, 1997.

OTSUBO, T:; MARUYAMA, K.; MAESAKI, S.; MIYAZAKI, Y.; TANAKA, E.; TAKIZAWA, T.; MORIBE, K.; TOMONO, K.; TASHIRO, T.; KOHNO, S. Long-circulating immunoliposomal amphotericin B against invasive pulmonary aspergillosis in mice. Antimicrob. Agents Chemother., v. 42, p. 40-44, 1998.

OTSUBO, T.; MARUYAMA, K.; MAESAKI, S.; MIYAZAKI, Y.; TANAKA, E.; TAKIZAWA, T.; MORIBE, K.; TOMONO, K.; TASHIRO, T.; KOHNO, S. Long-circulating immunoliposomal amphotericin B against invasive pulmonary aspergillosis in mice. Antimicrob. Agents Chemother., v. 42 , p. 40-44, 1999.

OWENS, D.; FLEMING, R.A.; RESTINO, M.S.; CRUZ, J.M.; HURD, D.D. Stability of amphotericin B 0.05 and $0.5 \mathrm{mg} / \mathrm{ml}$ in $20 \%$ fat emulsion. Am. J. Health-Syst. Pharm., v. 54, p. 683-685, 1997. 
PAHLS, S.; SCHAFFNER, A. Comparison of the activity of free and liposomal amphotericin $B$ in vitro and in a model of systemic and localized murine candidiasis. J. Infect. Dis., v. 169, p. 1057-1061, 1994.

PALLISTER, C.J.; JOHNSON, E.M.; WARNOCK, D.W.; ELLIOT, P.J.; REEVES, D.F. In-vitro effects of liposome-encapsulated amphotericin B (AmBisome) and amphotericin B-deoxycholate (Fungizone) on the phagocytic and candidacidal function of human polymorphonuclear leucocytes. J. Antimicrob. Chemother., v. 30, p. 313-320, 1992.

PALLISTER, C.J.; WARNOCK, D.W. Effect of antimicrobial and antineoplastic drugs alone and in combination on the phagocytic and candidacidal function of human polymorphonuclear leucocytes. $J$. Antimicrob. Chemother., v. 23, p. 87-94, 1989.

PATTERSON, T.F.; MINITER, P.; DIJKSTRA, J.; SZOKA, F.C.; RYAN, J.L.; ANDRIOLE, V.T. Treatment of experimental invasive aspergillosis with novel amphotericin B/cholesterol-sulfate complexes. J. Infect. Dis., v. 159, p. 717-724, 1989.

PERFECT, J.R.; WRIGHT, K.A. Amphotericin B lipid complex in the treatment of experimental cryptococcal meningitis and disseminated candidosis. J. Antimicrob. Chemother., v. 33, p. 73-81, 1994.

PFALLER, M.A.; DIEKEMA, D.J.; JONES, R.N.; MESSER, S.A.; HOLLIS, R.J. Trends in antifungal susceptibility of Candida spp. isolated from pediatric and adult patients with bloodstream infections: SENTRY antimicrobial surveillance program, 1997 to 2000. J. Clin. Microbiol., v. 40, p. 852-856, 2002.

PFALLER, M.A.; DIEKEMA, D.J.; MESSER, S.A.;HOYKEN, L.; HOLLIS, R.J; JONES, R.N. In vitro susceptibilities of rare Candida bloodstream isolates to ravuconazole and three comparative antifungal agents. Diagn. Microbiol. Infect. Dis., v. 48, p. 101-105, 2004.

PIANCASTELLI, S.; HAMDAN, J.S. Effect of amphotericin $\mathrm{B}$ on the lipids of different strains of Cryptococcus neoformans. Mycopathologia, v. 128, p. 85-89, 1994.

PONCE, E.; PECHÉRE, J.C. Activity of amphotericin B and itraconazole against intraphagocytic Candida albicans. Eur. J. Clin. Microbiol. Infect. Dis., v. 9, p. 738-744, 1990.
PONCE, E.; PECHÉRE, J.C. Activity of amphotericin B and itraconazole against intraphagocytic Candida albicans. Eur. J. Clin. Microbiol. Infect. Dis., v. 9, p. 738-744, 1990.

PRENTICE, H.G.; HANN, I.M.; HERBRECHT, R. A randomized comparison of liposomal versus conventional amphotericin for treatment of pyrexia of unknown origin in neutropenic patients. Br. J. Haematol., v. 98, p. 711-718, 1997.

RACIS, S.P; PLESCIA, O.J.; GELLER, H.M.; SCHAFFNER, C.P. Comparative toxicities of amphotericin $\mathrm{B}$ and its monomethyl ester derivative on glial cells in culture. Antimicrob. Agents Chemother., v. 34, p. 1360-1365, 1990.

RALPH, E.D.; BARBER, K.R.; GRANT, C.W.M. Liposomal amphotericin B: an effective, nontoxic preparation for the treatment of urinary tract infections caused by Candida albicans. Am. J. Nephrol., v. 11, p. 118-122, 1991.

RALPH, E.D.; KHAZINDAR, A.M.; BARBER, K.R.; GRANT, C.W.M. Comparative in vitro effects of liposomal amphotericin B, amphotericin B-deoxycholate, and free amphotericin $\mathrm{B}$ against fungal strains determined by using MIC and minimal lethal concentration susceptibility studies and time-kill curves. Antimicrob. Agents Chemother., v. 35, p. 188-191, 1991.

RAMOS, H.; SAINT-PIERRE-CHAZALET, M.; BOLARD, J.; COHEN, B.E. Effect of ketoconazole on lethal action of amphotericin B on Leishmania mexicana promastigotes. Antimicrob. Agents Chemother, v. 38, p. 1079-1084, 1994.

REDGRAVE, T.G.; MARANHÃO, R.C. Metabolism of protein-free lipid emulsion models of chylomicrons in rats. Biochim. Biophys. Acta, v. 835, p. 104-112, 1985.

REDGRAVE, T.G.; VASSILIOU, G.G.; CALLOW, M.J. Cholesterol is necessary for triacylglycerol-phospholipid emulsions to mimic the metabolism of lipoproteins. Biochim. Biophys. Acta v. 921, p. 157-157,1987.

RINGDÉN, O.; MEUNIER, F.; TOLLEMAR, J.; RICCI, P.; TURA, S.; KUSE, E.; VIVIANI, M.A.; GORIN, N.C.; KLASTERSKY, J.; FENAUX, P.; PRENTICE, H.G.; KSIONSKI, G. Efficacy of amphotericin B encapsulated in liposomes (AmBisome) in the treatment of invasive fungal infections in immunocompromised patients. $J$. Antimicrob. Chemother., v. 28, p. 73-82, 1991. 
SABRA, R.; TAKAHASHI, K.; BRANCH, R.A.; BARD, K.F. Mechanisms of amphotericin B-induced reduction of the glomerular filtration rate: a micropuncture study. J. Pharmacol. Exp. Ther, v. 253, p. 34-7, 1990.

SAINT-PIERRE-CHAZALET, M.; THOMAS, C.; DUPEYRAT, M.; GARY-BOBO, C.M. Amphotericin B-sterol complex formation and competition with egg phosphatidylcholine: a monolayer study. Biochim. Biophys. Acta., v. 944, p. 477-486, 1988.

SALLAH, S.; SEMELKA, R.C.; SALLAH, W.; VAINRIGHT, J.R.; PHILIPS, D.L. Amphotericin B lipid complex for the treatment of patients with acute leukemia and hepatosplenic candidiasis. Leukemia Res., v. 23, p. 995-999, 1999.

SANDERS, S.E.; BUCHI, K.N.; GODDARD, M.S.; LANG, J.K.; TOLMAN, K.G. Single dose pharmacokinetics and tolerance of a cholesteryl sulfate complex of amphotericin B administered to healthy volunteers. Antimicrob. Agents Chemother, v. 35, p. 1029-1034, 1991.

SCHÖFFSKI，P.; FREUND，M.; WUNDER，R.; PETERSEN, D.; KÖHNE, C.H.; HECKER, H.; SCHUBERT, U.; GANSER, A. Safety and toxicity of amphotericin B in glucose 5\% or intralipid 20\% in neutropenic patients with pneumonia or fever of unknown origin: randomized study. BMJ, v. 317, p. 379384. 1998.

SCHREIER, S.; FERREIRA, V.F.N.; LAMY-FREUND, T. ESR studies of molecular aspects of the mechanism of drug action: autoxidation of the polyene antibiotic amphotericin B. In: GOUIL, G, KHETRAPAL, C.L., EA. SARAN., Eds. Magnetic resonance in biology and medicine. New Delhi: Iata McGraw-Hill, 1985. p. 319-331.

SCHÜRMANN, D.; MARQUES, B.M.; GRÜNEWALD, T.; POHLE, H.D.; HAHN, H.; RUF, B. Safety and efficacy of liposomal amphotericin B in treating AIDSassociated disseminated cryptococcosis. J. Infect. Dis., v. 164, p. 620-622, 1991.

SERRANO, M. C.; VALVERDE-CONDE, A.; CHÁVEZ, M.; BERNAL, S.; CLARO, R.M.; PEMÁN, J.; RAMIREZ, M.; MARTIN-MAZUELOS, E. In vitro activity of voriconazole, itraconazole, caspofungiin, anidulafungin(VER002, LY303366) and amphotericin B against Aspergillus spp. Diagn. Microbiol. Infect. Dis., v. 45, p. 131-135, 2003.
SHADKCHAN, Y.; SEGAL, E. Treatment of experimental candidosis with amphotericin B - Intralipid admixtures in immunocompromised mice. J. Antimicrob. Chemother., v. 48, p. 245-251, 2001

SINGH, M; RAVIN, L.J.. Parenteral Emulsions As Drug Carrier Systems. J. Parenter. Sci. Technol., v. 40, p. 34-41, 1986.

SOKOL-ANDERSON, M.L.; BRAJTBURG, J.; MEDOFF, G. Amphotericin B-induced oxidative damage and killing of Candida albicans. J. Infect. Dis., v. 154, p. 76-83, 1986.

SOKOL-ANDERSON, M.L.; SLIGH J.E.; ELBERG, S.; BRAJTBURG, J.; KOBAYASHI, G.S.; MEDOFF, G. Role of cell defence against oxidative damage in the resistance of Candida albicans to the killing effect of amphotericin B. Antimicrob. Agents Chemother, v. 32, p. 702-705, 1988.

SOUZA, L.C.; CAMPA, A. Pharmacological parameters of intravenously administered amphotericin B in rats: comparison of the conventional formulation with amphotericin B associated with a triglyceride-rich emulsion. J. Antimicrob. Chemother., v. 44, p. 77-84, 1999.

SOUZA, L.C.; MARANHÃO, R.C.; SCHREIER, S.; CAMPA, A. In-vitro and iv-vivo studies of the decrease of amphotericin B toxicity upon association with a triglyceride-rich emulsion. J. Antimicrob. Chemother, v. 32, p. 123-132, 1993.

SOUZA, L.C.; SALDIVA, P.H.N.; CAMPA, A. Lipid emulsion reduces subacute tocixity of amphotericin B: a histopathological study. Exp. Toxic. Pathol., v. 52, p. 169$175,2000$.

SWENSON, C.E.; PERKINS, W.R.; ROBERTS, P.; AHMAD, I.; STEVENS, R.; STEVENS, D.A.; JANOOF, A.S. In vitro and in vivo antifungal activity of amphotericin B lipid complex: are phospholipases important? Antimicrob. Agents Chemother., v. 42, p. 767-771, 1998.

SZOKA,F.C.; MILHOLLAND, D.; BARZA, M. Effect of lipid composition and liposome size on toxicity and in vitro fungicidal activity of liposome-intercalated amphotericin B. Antimicrob. Agents Chemother., v. 31, p. 421-429, 1987.

TABOSA DO EGITO, E.S.; FESSI, H.; APPEL, M.; BARRAT, G.; LEGRAND, P.; BOLARD, J.; DEVISSAGUET, J-PH. A morphological study of an amphotericin B emulsion-based delivery system. Int. $J$. Pharm., v.145, p. 17-27, 1996. 
TEERLINK, T.; DE KRUIJFF, B.; DEMEL, R.A. The action of pimaricin, etruscomycin and amphotericin $\mathrm{B}$ on liposomes with varying sterol content. Biochim. Biophys. Acta, v. 599, p. 484-492, 1980.

TOLLEMAR, J.; DURAJ, F.; ERICZON, B.G. Liposomal amphotericin B treatment in a 9-month-old liver recipient. Mycoses, v. 33, p. 251-252, 1990.

TOLLEMAR, J.; RINGDÉN, O.; ANDERSSON, S.; SUNDBERG, B.; LJUNGMAN, P.; TYDÉN, G. Randomized double-blind study of liposomal amphotericin B (AmBisome) prophylaxis of invasive fungal infections in bone marrow transplant recipients. Bone Marrow Transplant., v. 12, p. 577-582, 1993.

VAIDYA, S.J.; SEYDEL, C.; PATEL, S.R.; ORTIN, M. Anaphylactic reaction to liposomal amphotericin B. Ann. Pharmacother., v.36, p. 1480-1481, 2002.

VALERO, G.; GRAYBILL, J.R. Successful treatment of cryptococcal meningitis with amphotericin B colloidal dispersion: report of four cases. Antimicrob. Agents Chemother., v. 39, p. 2588-2590, 1995.

VAN ETTEN, E.W.M.; GROOT, C.H.; BAKKERWOUDENBERG, I.A.J.M. Efficacies of amphotericin Bdesoxycholate (Fungizone), liposomal amphotericin B (AmBisome) and fluconazole in the treatment of systemic candidosis in immunocompetent and leucopenic mice. $J$. Antimicrob. Chemother, v. 32, p. 723-739, 1993.

VAN ETTEN, E.W.M.; SNIJDERS, S.V.; BAKKERWOUDENBERG, I.A.J.M. Interactions of liposomal amphotericin B with extracellular and intracellular Candida albicans.J. Antimicrob. Chemother., v. 36, p. 961-974, 1995.

VAN ETTEN, E.W.M.; VAN VIANEN, W.; HAK, J.; BAKKER-WOUDENBERG, I.A. Activity of liposomal amphotericin $\mathrm{B}$ with prolonged circulation in blood versus those of AmBisome and Fungison against peritoneal macrophages. Antimicrob. Agents Chemother., v. 42, p. 2437-2439, 1998.

VAN ETTEN, W.M.; OTTE-LAMBILLION, M.; VAN VIANEN, W.; ten KATE, M.T.; BAKKERWOUDENBERG, I.A.J.M. Biodistribution of liposomal amphotericin B (AmBisome) and amphotericin Bdesoxycholate (Fungizone) in uninfected immunocompetent mice and leucopenic mice infected with Candida albicans.J. Antimicrob. Chemother., v. 35, p. 509-519, 1995.
VANDEPUTTE, J.; WACHTEL, J.L.; STILLER, E.T. Amphotericin A and B antifungal antibiotics produced by a Streptomycete. II The isolation and properties of the crystalline amphotericins. Antibiot. Annu., v. 1955-1956, p. 587-591, 1956.

VARLAM, D.E.; SIDDIQ, M.M.; PARTON, L.A.; RÜSSMANN, H. Apoptosis contributes to amphotericin B- induced nephrotoxicity. Antimicrob. Agents Chemother., v. 45, n. 3, p. 679-685, 2001.

VASCONCELLOS, L.S.; MOURAO, P.H.O.; PAIVA, L.F.R. Aumento da positividade de fungemias isoladas em hemoculturas no setor de microbiologia do Laboratório Central do HC-UFMG nos últimos 6 anos. In: CONGRESSO BRASILEIRO DE PATOLOGIA CLÍNICA/MEDICINA LABORATORIAL, 38, Florianópolis, 2004. Resumos. Florianópolis: Sociedade Brasileira de Patologia Clínica/Medicina Laboratorial, 2004. res. 514.

VERTUT-CROQUIN, A.; BOLARD, J.; CHABBERT, M.; GARY-BOBO, C. Differences in the interaction of the polyene antibiotic amphotericin B with cholesterol-or ergosterol-containing phospholipid vesicles. A circular dichroism and permeability study. Biochemistry, v. 22, p. 2939-2944, 1983.

WALSH, T.; FINBERG, R.W.; ARNDT, C.; HIEMENZ, J.; SCHWARTZ, C.; BODENSTEINER, D.; PAPPAS, P.; SEIBEL, N.; GREENBERG, R.N.; DUMMER, S.; SCHUSTER, M.; HOLCENBERG, J.S. Liposomal amphotericin B por empirical therapy in patients with persistent fever and neutropenia. NEJM, v. 340, p. 764 $771,1999$.

WALSH, T.J.; YELDANDI, V.; MCEVOY, M.; GONZALES, C.; CHANOCK, S.; FREIFELD, A.; SEIBEL, N.I.; WHITCOMB, P.O.; JARASINSKI, P.; BOSWELL, G.; BEKERSKY, I.; ALAK, A.; BUELL, D.; BARRET, J.; WILSON, W. Safety, tolerance, and pharmacokinetics of a small unilamellar liposomal formulation of amphotericin B (AmBisome) in neutropenic patients. Antimicrob. Agents Chemother., v. 42, p. 2391-2398, 1998.

WASAN, T.J.; BRAZEAU, G.A.; KEYHANI, A.; HAYMAN, A.C.; LOPEZ-BERESTEIN, G. Roles of liposome composition and temperature in distribution of amphotericin B in serum lipoproteins. Antimicrob. Agents Chemother, v. 37, p. 246-250, 1993. 
WASAN, T.J.;ROSENBLUM, M.G.; CHEUNG, L.; LOPEZ-BERESTEIN, G. Influence of lipoproteins on renal cytotoxicity and antifungal activity of amphtoericin. Antimicrob. Agents Chemother., v. 38, p. 223-227, 1994.

WHITE, M.H.; ANAISSIE, R.J.; KUSNE, S.; WINGARD, J.R.; HIEMENZ, J.H.; CANTOR, A.; GURWITH, M.; DU MOND, C.; MAMELOK, R.D.; BOWDEN, R.A. Amphotericin B colloidal dispersion vs. amphotericin B as therapy for invasive aspergillosis. Clin. Infect. Dis., v. 24, p. 635-642, 1997.

WHYTE, B.S.; PETERSON, R.P.; HARTSEL, S.C. Amphotericin $\mathrm{B}$ and nystatin show different activities on sterol free vesicles. Biochem. Biophys. Res. Commun., v. 164, p. 609-614, 1989.

WILSON, E.; THORSON, L.; SPEERT, D.P. Enhancement of macrophage superoxide anion production by amphotericin B. Antimicrob. Agents Chemother, v. 35, p. 796-800, 1991.

WILSON, R.; FELDMAN, S. Toxicity of amphotericin B in children with cancer. Arch. Pediatr. Adolesc. Med., v. 133, p. 731-734, 1979.
WINGARD, J.R.; WHITE, M.H.; ANAISSIE, E.; RAFFALli, J.; GOODMAN, J.; ARRIETA, A. A randomized, double-blind comparative trial evaluating the safety of liposomal amphotericin B versus amphotericin B lipid complex in the empirical treatment of febrile neutropenia. Clin. Infec. Dis. v. 31, p. 1115 $1163,2000$.

WU, T.C. On the development of antifungal agents: perspective of the U.S. Food and Drug Administration. Clin. Infect. Dis., v. 19, p. 54-58, 1994.

WU, T.C. On the development of antifungal agents: perspective of the U.S. Food and Drug Administration. Clin. Infect. Dis., v. 19, p. 54-58, 1994.

YOUNG, L.Y.; HULL, C.M.; HEITMAN, J. Disruption of ergosterol biosynthesis confers resistance to amphotericin B in Candida lusitaniae. Antimicrob. Agents Chemother., v. 47, p. 2717-2724, 2003.

ZYGMUNT, W.A. Intracellular loss of potassium in Candida albicans after exposure of polyene antifungal antibiotics. Appl. Microbiol., v. 14, p. 953-956, 1966.

Recebido para publicação em 02 de março de 2005. Aceito para publicação em 09 de março de 2006. 